\title{
Shape effects on undrained capacity of mudmat foundations under multi- directional loading
}

\author{
X. Feng ${ }^{1}$, S. Gourvenec ${ }^{1}$ and Z. Shen ${ }^{2}$
}

Published in Ocean Engineering 135:221-235

http://dx.doi.org/10.1016/j.oceaneng.2017.02.033

\author{
${ }^{1}$ Xiaowei FENG \\ Centre for Offshore Foundation Systems, a node of the ARC Centre of Excellence for \\ Geotechnical Science and Engineering \\ University of Western Australia \\ 35 Stirling Highway, Crawley \\ Perth, WA 6009 \\ Australia \\ Tel: +61 864882473 \\ Fax: +61 864881044 \\ Email: xiaowei.feng@uwa.edu.au \\ ${ }^{1}$ Susan GOURVENEC \\ Centre for Offshore Foundation Systems, a node of the ARC Centre of Excellence for \\ Geotechnical Science and Engineering \\ University of Western Australia \\ Tel: +61 864883995 \\ Email: susan.gourvenec@uwa.edu.au

\section{Zhichao SHEN} \\ State Key Laboratory of Hydraulic Engineering Simulation and Safety \\ Tianjin University \\ 92 Weijin Road, Nankai District \\ Tianjin, 300072 \\ China \\ Visiting scholar at Centre for Offshore Foundation Systems, University of Western Australia \\ Email: shenzhch@163.com
}

No. of words: 5165 (without abstract and references)

No. of tables: 3

No. of figures: 19 


\title{
Shape effects on undrained capacity of mudmat foundations under multi- directional loading
}

\author{
X. Feng ${ }^{1}$, S. Gourvenec ${ }^{1}$ and Z. Shen ${ }^{2}$
}

\section{ABSTRACT}

The results presented in this paper systematically quantify shape effects on undrained capacity of rectangular mudmat foundations under multi-directional loading for a practical range of soil shear strength heterogeneity. Mudmat foundations are extensively deployed to support infrastructure for subsea production systems, are typically rectangular in plan, ranging from square to a width-to-length aspect ratio of 0.2 , and are subject to multi-directional loading from the attached pipelines and jumpers. The load-carrying capacity of rectangular mudmats on deposits with undrained shear strength linearly increasing with depth is analysed by the finite-element method, and presented in the form of 'failure envelopes'. The results show that shape effects are significant and are dependent on the degree of soil strength heterogeneity and loading direction (relative to the orthogonal axes of the mudmat). General algebraic expressions are established that systematically define the coupled effects of width-to-length aspect ratio of the mudmats and the degree of strength heterogeneity of the subsoil. Expressions describing the uniaxial ultimate limit states and the normalised failure envelopes under multi-directional loading can be programmed into a calculation tool for automating optimised mudmat sizing for a range of foundation geometry and soil strength heterogeneity.

\section{KEYWORDS}

Seabed foundations; failure; bearing capacity; subsea systems; geotechnical design 


\section{INTRODUCTION}

Subsea shallow foundations, referred to as mudmats, are widely employed to support subsea infrastructure, such as pipeline end terminations and manifolds for offshore oil and gas developments. Mudmat foundations are generally rectangular in plan, featuring peripheral and internal 'skirts' in soft seabed conditions to distribute the foundation loads to deeper stronger soil. The required footprint area of a subsea mudmat to ensure load-carrying capacity is governed by the multi-directional load response, which is dependent on the coupled effects of foundation aspect ratio and soil strength heterogeneity of the seabed.

The bearing capacity of rectangular mudmats is usually based on the plane strain solution for an infinitely-long strip foundation (Davis and Booker, 1973; Terzaghi, 1943). The maximum vertical load $V_{d}$ that a rectangular foundation can support under undrained conditions is conventionally expressed by equation (1) (ISO, 2003)

$\mathrm{V}_{\mathrm{d}}=\mathrm{F}\left(\mathrm{N}_{\mathrm{c}} \mathrm{s}_{\mathrm{u} 0}+\frac{\rho \mathrm{B}^{\prime}}{4}\right) \mathrm{K}_{\mathrm{c}} \mathrm{A}^{\prime}$

Where, $F$ is the correction factor given as a function of foundation roughness and $\rho B^{\prime} / s_{u 0}, \rho$ is the gradient of the increase of undrained shear strength with depth; $\mathrm{s}_{\mathrm{u} 0}$ is the undrained shear strength of the soil at foundation level, $\mathrm{N}_{\mathrm{c}}$ is the plane strain bearing capacity factor for uniform shear strength $(2+\pi)$, $\mathrm{B}^{\prime}$ is the minimum effective lateral foundation dimension, $\mathrm{A}^{\prime}$ is the effective area of the foundation depending on the load eccentricity, and $\mathrm{K}_{\mathrm{c}}$ is the superposing modification factor accounting for load inclination, foundation shape, etc. An empirical shape factor to consider the end effects of the rectangular foundations is the most widely adopted Skempton's expression (Skempton, 1951), which adjusts bearing capacity linearly with the width-to-length aspect ratio; for a square foundation the ultimate limit state is taken as $20 \%$ higher than for a strip foundation. Most previous research on the shape factors for bearing capacity of rectangular foundations has focused on the constant undrained 
shear strength. Various methodologies have been employed, including plastic limit analysis (Michalowski, 2001), finite-element analysis (Gourvenec et al., 2006; Merifield and Nguyen, 2006; Zhu and Michalowski, 2005) and finite-element limit analysis (Lyamin and Sloan, 2000; Salgado et al., 2004). However, the deep-water seafloor is generally fine-grained soil with undrained shear strength linearly increasing with depth. In addition, the external loads applied to subsea mudmats are multi-directional rather than purely vertical, resulting from installation and operational forces from pipeline and jumper connections to the structures supported by mudmats. For combined loading conditions, Gourvenec (2007) examined shape effects on undrained load-carrying capacity of rectangular foundations under co-planar loading on soil with uniform undrained shear strength with depth. The response of rectangular mudmats subjected to fully three-dimensional loading was investigated by Feng et al. (2014) for subsoil with varying undrained shear strength heterogeneity. However, only the mudmats with aspect ratio of 0.5 were considered since that the mudmat size was constrained by the particular dimension of the rectangular opening, i.e. the moon-pool, on the installation vessel through which the mudmats are laid down onto the seabed. Other constraints over dimensions of pre-installed mudmats include the stinger structure for S-lay and the geometrical envelope of the tower for J-lay (Fontaine and Dilosquer, 2014), and thus may vary with a specific type of installation vessel. Furthermore, for the recent concept of post-installed mudmats presented in Fontaine and Dilosquer (2014), the constraint of an installation vessel over the dimension of the mudmats can be relaxed by integrating the mudmat installation with the pipe-laying process. Therefore, the aspect ratio and dimensions of rectangular mudmats may be variable, yet multi-directional load-carrying capacity has not been systematically established for rectangular foundations with varying aspect ratios.

The work presented in this paper examined the undrained load-carrying capacity of rectangular mudmats of varying aspect ratios on soil with varying degrees of strength 
heterogeneity under general combined loading conditions. The finite-element (FE) method was employed and the load-carrying capacity of the mudmats is presented in the form of failure envelopes, which allows for explicit consideration of the independent load components, foundation geometry and soil conditions, rather than superposing modification factors. The effects of foundation aspect ratio and degree of soil strength heterogeneity on the shape of the failure envelopes are systematically examined. General algebraic expressions are proposed to describe the normalised failure envelopes, enabling developing an automatic calculation tool for routine use for the geotechnical design of subsea mudmats in deep water.

\section{BOUNDARY CONDITIONS}

The sign convention for each component used in this study is shown in Figure 1. The notation adopted for loads is summarised in Table 1. The ultimate vertical, horizontal and moment capacities are defined as the pure load-carrying capacity in the absence of other loading. Rectangular mudmats with width-to-length aspect ratio of $\mathrm{B} / \mathrm{L}=0.2,0.33,0.5,0.75$ and 1 (square) were considered to cover the range in engineering practice. The width $\mathrm{B}$ of the mudmat is kept at $5 \mathrm{~m}$ and the length varies according to the prescribed aspect ratio. The shallowly embedded skirted mudmat was modelled as an equivalent surface foundation with a full-tension skirt-soil interface, as commonly adopted to conceptually represent the effect of skirts on uplift and overturning resistance (Bransby and Randolph, 1998; Gourvenec and Randolph, 2003; Taiebat and Carter, 2000; Tani and Craig, 1995). The idealisation is not expected to affect the underlying mechanisms accompanying failure, but can underestimate capacity by neglecting the work done by shearing in the soil above skirt tip level. Recent studies found that the shape of the normalised V-H, V-M, M-M and H-M failure envelopes is insensitive of the skirt depth of the mudmat foundations (Feng et al., 2014). The effect of embedment depth on the normalised failure envelopes for biaxial horizontal loading $(\mathrm{H}-\mathrm{H})$ has been assessed thoroughly in Feng et al. (2016). Therefore, the depth effect is not explicitly 
investigated in current study. The undrained soil shear strength $\mathrm{s}_{u}$ was assumed to be uniform or increase linearly with depth according to $s_{u}=s_{u 0}+\rho z$, as shown in Figure 1, where $s_{u 0}$ is the shear strength at mudmat level and $\rho$ is the gradient of soil shear strength. The degree of soil strength heterogeneity is defined as $\kappa=\rho \mathrm{B} / \mathrm{s}_{\mathrm{u} 0}$, ranging from 0 (uniform soil) to 20 , to bracket field conditions. The lower end of the range is relevant to over-consolidated deposits and the latter end of the range to softer normally consolidated deposits, providing in either case the drainage conditions and loading rate are such that the soil response remains undrianed. For the uniform soil, the undrained shear strength is kept constant at $5 \mathrm{kPa}$, whereas the gradient of the soil undrained shear strength maintains $1 \mathrm{kPa} / \mathrm{m}$ and the shear strength at mudmat level $\mathrm{s}_{\mathrm{u} 0}$ is determined according to the prescribed value of $\mathrm{\kappa}$ for a heterogeneous strength profile. The soil parameters employed in the FE models are listed in

Table 2. All results are presented in terms of dimensionless quantities as summarised in Table 1 and are independent of the absolute mudmat dimensions and the adopted soil shear strength profiles. However, additional analyses are carried out using different combinations of $\mathrm{B}, \rho$ and $\mathrm{su}_{\mathrm{u} 0}$ to reassure the readers of the normalisation strategy as shown later in this paper.

The mudmats are subjected to general combined vertical (V), horizontal $(\mathrm{H})$ and moment (M) loading. The torsion is excluded from present analyses but the effect of torsion is assessed later in this paper using the proposed design approach in Feng et al. (2014) for rectangular mudmats under fully three-dimensional loading.

\section{FINITE ELEMENT MODEL}

\subsection{Geometry}

All the finite element analyses were carried out using the software ABAQUS (Dassault Systèmes, 2011). Five fully three-dimensional models were established to investigate the effect of varying aspect ratios on bearing capacity. Each mesh maintained the same geometry and discretisation on the central plane through the centroid of the mudmat. More elements 
were required in the longitudinal direction of the more slender mudmats to maintain a consistent element size across the models. For example, the mesh for the $\mathrm{B} / \mathrm{L}=0.2$ mudmat (Figure 2a) comprises 61,300 linear 8-node continuum hybrid elements (refer to element type $\mathrm{C} 3 \mathrm{D} 8 \mathrm{H}$ in the ABAQUS element library), and the mesh for the $\mathrm{B} / \mathrm{L}=1$ mudmat comprises 41,500 elements. The hybrid element formulation uses a mixture of displacement and stress variables (as opposed to solely displacement) to approximate the equilibrium equations and compatibility conditions. Hybrid elements are recommended for modelling the response of incompressible and near-incompressible materials (such as is appropriate for undrained soil conditions). Only the half view of each mesh is shown in Figure 2 to illustrate the mesh consistency on the mid-point central plane.

The mesh boundaries were set a distance of 3B from the edges of the mudmat and 3B beneath the mudmat, sufficiently remote from the mudmat and applied loading that the failure mechanisms were unaffected. Mesh nodes at vertical boundaries were constrained to prevent out-of-plane displacement, while those at the base of the mesh were fully constrained in all three coordinate directions. Relatively fine mesh was provided in the vicinity of the edges of the mudmat $(\sim 1 \% \mathrm{~B})$ and immediately below the mudmat $(\sim 0.3 \% \mathrm{~B})$ to precisely capture the failure loads and mechanisms.

The model for a strip foundation was also built as a reference case with the same geometry and mesh discretisation on the mid-point central plane as shown in Figure 2 for rectangular mudmats.

\subsection{Material properties and interface conditions}

The undrained soil condition was represented with a linear elastic perfectly plastic constitutive law obeying the Tresca failure criterion. A constant modulus ratio of $E_{u} / s_{u}=1000$ was prescribed to give a relatively high rigidity index $G / s_{u}$ of 336 , where $G$ is the shear modulus of the soil, enabling failure loads to be mobilised with relatively small deformation 
to aid numerical convergence by avoiding excessive iterations triggered by mesh distortion. To avoid numerical difficulties the Poisson's ratio of $v=0.49$ was adopted to approximate the constant volume response of soil under undrained conditions. The geostatic stress in the soil was established using the prescribed submerged unit weight $\gamma^{\prime}$ of $6 \mathrm{kN} / \mathrm{m}^{3}$ and a lateral stress coefficient of unity. The ultimate limit state of the soil is unaffected by the initial stress condition prior to mudmat loading. The mudmat was modelled as a weightless, rigid body, with the load reference point located at the midpoint of the mudmat base.

In practice, subsea mudmats are typically equipped with short 'skirts' that penetrate into the seabed confining a plug of soil leading to a rough, soil-soil interface at foundation level and potential for transient tensile resistance due to passive suction developed within the soil plug. Therefore, the interface between the underside of the equivalent surface mat foundation and the subsoil was taken to be rough in shear with no detachment permitted (i.e. fully bonded). If the mudmats were truly skirtless in practice, the effect of adopting a solution assuming a full tension interface should be considered (Shen et al., 2016). The capacity of the foundation can be also affected by the interface roughness when the vertical loading is dominant. For mudmats, however, the dead weight of the foundation and the superstructure is typically a relatively low proportion of the vertical capacity and geotechnical design is governed by the operational H, M and T. Therefore, a rough interface is considered an acceptable assumption for this study.

\subsection{Detecting the failure envelopes}

Failure envelopes under combined loading conditions were evaluated using two separate techniques:

(a) displacement-controlled 'swipe' loading paths, as originally introduced in physical model tests by Tan (1990), in which a foundation was initially loaded to failure in one direction followed by loading in a second direction with the incremental displacement being 
unidirectional. Side swipe paths have been shown to work well in V-H and V-M load spaces to predict failure envelopes (Gourvenec and Randolph, 2003). In this paper, the 'modified' swipe analyses proposed by Taiebat and Carter (2010) were conducted, in which the foundation is loaded vertically to failure and then, in the second portion of loading, the incremental vertical displacement, $\delta_{\mathrm{v}}$, reduces from its maximum value (downwards positive) using a cosine function period. The incremental horizontal displacement, $\delta_{\mathrm{h}}$, and incremental rotation $\delta_{\theta}$, increase from zero using a sine function period. When $\delta_{\mathrm{v}}$ reaches zero, $\delta_{\mathrm{h}}$ and $\delta_{\theta}$ reach their maximum values. After this stage, $\delta_{\mathrm{v}}$ becomes negative (upwards) while $\delta_{\mathrm{h}}$ and $\delta_{\theta}$ reduce to zero at the end of the analysis. This type of analyses has improved accuracy and efficiency, since the derived load paths lie entirely on the failure envelopes.

(b) fixed-ratio probe tests, both displacement-controlled and load-controlled. Probe tests were conducted in H-M and M-M load spaces. The displacement-controlled probe tests were considered to result in the most accurate failure points on the failure envelopes, but additional load-controlled analyses were conducted to cover the areas not probed by the displacementcontrolled analyses. Only a single point can be provided on the failure envelope by a fixed displacement ratio probe test and failure is defined where the normal to the load path matches the prescribed displacement ratio in accordance with the associated flow rule (Bransby and Randolph, 1998). The loading path from a load-controlled probe terminates when it reaches failure envelope, indicated by failing the convergence check. Very small load increments are necessary as failure is approached in order not to overshoot the failure envelope.

\section{RESULTS}

\subsection{Pure uniaxial capacities}

The pure uniaxial quantities in this section are presented as the corresponding dimensionless quantities as summarised in Table 1. 
Vertical bearing capacity of the rectangular mudmats on soil with uniform strength with depth is plotted in Figure 3a together with previous solutions derived from FE limit analysis (Salgado et al., 2004), and FE analysis (Gourvenec et al., 2006). Current FE results compare well ( $\pm 1.0 \%)$ with those obtained from Gourvenec et al. (2006) and fall midway between the bounds presented by Salgado et al. (2004). Comparison of the bearing capacity of the rectangular foundations with various aspect ratios on the heterogeneous soil is not straightforward. Effects of soil heterogeneity on undrained vertical bearing capacity have been investigated for rectangular mudmats with $\mathrm{B} / \mathrm{L}=0.5$ in Martin et al. (2015). Figure 3b shows the overall consistency of current FE results with the numerical upper-bound solution (Martin et al., 2015). The vertical capacity as a function of aspect ratio is expressed in terms of a shape factor, expressed as

$$
\mathrm{s}_{\mathrm{C}}=\frac{\mathrm{q}_{\mathrm{ult}}}{\mathrm{q}_{\mathrm{ult}(\mathrm{B} / \mathrm{L}=0)}}
$$

where qult and $\mathrm{qult}_{\mathrm{B} / \mathrm{L}=0)}$ represent the ultimate bearing pressure of the rectangular and strip foundations for given degree of soil heterogeneity, respectively.

For relatively uniform soil $(\kappa \leq 1)$, the soil failure mechanism at the central point plane transfers from a Prandtl (1921) type beneath a slender foundation $(\mathrm{B} / \mathrm{L}<0.2)$ to a Kusakabe et al. (1986) type as the aspect ratio increases (Figure 4a). Figure 5 shows that as the degree of soil heterogeneity increases the shape factor reduces, becoming less than unity for values of $\kappa$ larger than about 2. This is because the double-wedge type mechanism (Bransby \& Randolph, 1998) becomes the critical failure mode for higher soil strength heterogeneity with diminishing rigid wedge beneath the foundation, irrespective of the aspect ratios (Figure 4b). The reduction in shape factor becomes increasingly significant as the mudmat varies from a more slender rectangle to a square, since the plane strain condition prevails in the soil beneath a longer foundation. 
Accounting for the coupling effect of mudmat aspect ratio and soil heterogeneity, the vertical bearing capacity can be express as equation (3).

$\frac{\mathrm{V}_{\mathrm{ult}}}{\mathrm{As}_{\mathrm{u} 0}}=\frac{\mathrm{q}_{\mathrm{ult}}}{\mathrm{s}_{\mathrm{u} 0}}=5.28\left[1+0.17 \frac{\mathrm{B}}{\mathrm{L}}-0.06\left(\frac{\mathrm{B}}{\mathrm{L}}\right)^{2}\right]\left[1+\left(0.27-0.1 \frac{\mathrm{B}}{\mathrm{L}}\right) \cdot \kappa^{0.71+0.04 \mathrm{~B} / \mathrm{L}}\right]$

where the value of 5.28 is the derived vertical capacity factor $\mathrm{N}_{c}$ for strip foundations on homogenous soil, over-predicting the exact solution of $(2+\pi)$ by less than $3 \%$. The overall quality of the prediction is shown in Figure 6. Equation (3) yields good predictions for the vertical capacities for all aspect ratios and soil strength heterogeneity, with the discrepancy up to $3 \%$ for a slender foundation of $\mathrm{B} / \mathrm{L}=0.2$ on soil with high $\kappa$ values.

The horizontal capacity for a surface mudmat is theoretically the product of the mudmat base area A and soil shear strength at mudmat base level suo, i.e.

$\mathrm{H}_{\mathrm{xult}}=\mathrm{H}_{\mathrm{yult}}=\mathrm{As}_{\mathrm{u} 0}$

The over-prediction by FE increases slightly with the increasing degree of soil strength heterogeneity due to the non-zero thickness of interface elements, up to $6 \%$ in $\mathrm{H}_{\mathrm{xult}}$ and $5 \%$ in $\mathrm{H}_{\text {yult }}$ for the case of $\kappa=20$.

Sparse literature is available for the analytical solutions of the ultimate moment capacity for rectangular foundations. Figure 7 shows the consistency of ultimate moment capacity calculated in this study with the upper-bound solutions derived by Martin et al. (2015) for rectangular foundations with $\mathrm{B} / \mathrm{L}=0.5$. The following expressions are suggested for predicting the moment capacity of rectangular mudmats based on the FE results. For the moment capacity about the $\mathrm{y}$ - axis of the mudmat, a single expression can be used for all $\mathrm{B} / \mathrm{L}$ and $\kappa$

$$
\frac{\mathrm{M}_{\text {yult }}}{\mathrm{ABs}_{\mathrm{u} 0}}=0.72\left[1+0.26 \frac{\mathrm{B}}{\mathrm{L}}-0.02\left(\frac{\mathrm{B}}{\mathrm{L}}\right)^{2}\right]\left[1+\left(0.24-0.03 \frac{\mathrm{B}}{\mathrm{L}}\right) \cdot \kappa^{0.79-0.03 \mathrm{~B} / \mathrm{L}}\right]
$$


where the value of 0.72 is the FE results of moment capacity factor for strip foundations on homogeneous soil, approximately 4\% higher than the upper-bound solution of 0.69 (Randolph and Puzrin, 2003).

For the moment capacity about the $\mathrm{x}$ - axis of the mudmat

$$
\begin{array}{ll}
\frac{\mathrm{M}_{\text {xult }}}{\mathrm{ALs}_{\mathrm{u} 0}}=0.72\left[1+0.26 \frac{\mathrm{L}}{\mathrm{B}}-0.02\left(\frac{\mathrm{L}}{\mathrm{B}}\right)^{2}\right]\left[1+\left(0.16+0.05 \frac{\mathrm{L}}{\mathrm{B}}\right) \cdot \kappa^{0.8-0.04 \mathrm{~L} / \mathrm{B}}\right] & \text { for } \mathrm{L} / \mathrm{B} \leq 3 \\
\frac{\mathrm{M}_{\text {xult }}}{\mathrm{AL} \mathrm{s}_{\mathrm{u} 0}}=0.72\left[1+0.26 \frac{\mathrm{L}}{\mathrm{B}}-0.02\left(\frac{\mathrm{L}}{\mathrm{B}}\right)^{2}\right]\left[1+\left(0.385-0.025 \frac{\mathrm{L}}{\mathrm{B}}\right) \cdot \kappa^{0.62+0.02 \mathrm{~L} / \mathrm{B}}\right] & \text { for } 3<\mathrm{L} / \mathrm{B} \leq 5
\end{array}
$$

The piece-wised simulation of equation (6) considers the more significant three-dimensional effect involved in pure $M_{x}$ for a more slender mudmat (L/B > 3), where the 'wedge-scoopwedge’ failure mechanism identified by Bransby and Randolph (1998) begins to govern failure over a simple ‘prismatic scoop’ mechanism (Gourvenec, 2007) which is found in other cases. For a square mudmat of $\mathrm{B} / \mathrm{L}=1$, equation (6)a reduces to equation (5), yielding identical prediction of the moment capacity about the x- and y-axis. Equations (5) and (6) underestimates the moment capacity less than $6 \%$ in both directions for relatively stubby foundations on soil with high $\kappa$ ratios.

Spot checks on $\kappa=10$ using different combinations of $\rho, \mathrm{B}$ and suo as shown in Table 3 were carried out for a rectangular foundation with $\mathrm{B} / \mathrm{L}=0.5$. Identical results of pure uniaxial capacities were obtained, indicating that the dimensionless capacities are independent of the absolute mudmat dimensions and the soil shear strength profiles. To reassure the applicability of the proposed algebraic formulas, additional analyses were conducted for different aspect ratios $(\mathrm{B} / \mathrm{L}=0.25$ and 0.625$)$, and for different $\kappa$ ratios $(\kappa=0,0.5,4,8,12,15$ and 20$)$. The expressions agree well with the corresponding predictions derived from FE analyses, as shown in the Appendix. 


\subsection{Combined V-H capacity}

The bearing capacity of mudmat foundation under inclined vertical load is assessed by failure envelopes in the $\mathrm{V}-\mathrm{H}$ loading plane. The failure envelope for vertical and horizontal loading is generally expressed in terms of Green's plasticity solution (Green, 1954). The envelope is exact for a surface strip foundation on soil with homogeneous strength with depth, but has also been found to give a close approximation for any linearly varying shear strength profile (i.e. different values of $\kappa$ ) and also for circular foundations (Gourvenec and Randolph, 2003). However, for rectangular foundation geometry, the failure envelope is affected by the aspect ratio and the plane of loading. The FE results show that, for given degree of soil heterogeneity, the effect of foundation aspect ratio is minimal in the normalised $\mathrm{V}-\mathrm{H}_{\mathrm{x}}$ space, whereas the normalised $\mathrm{V}-\mathrm{H}_{\mathrm{y}}$ failure envelopes contract as the width-to-length aspect ratio increases (Figure 9). Green’s solution generally yields reasonable predictions for failure envelopes in normalised $\mathrm{V}-\mathrm{H}_{\mathrm{x}}$ space $\left(\theta=0^{\circ}\right)$, but significantly underestimates the failure envelopes for the case when the horizontal load is parallel to the long side of the foundation, i.e. $\theta=90^{\circ}$ for all $\mathrm{B} / \mathrm{L}$ and $\kappa$. The normalised $\mathrm{V}-\mathrm{H}$ failure envelopes can be described using equation (7)

$$
\begin{array}{ll}
\mathrm{h}=\left[1-(2 \mathrm{v}-1)^{1 / \mathrm{n}}\right]^{2 / 3} & \text { for } 0.5<\mathrm{v} \leq 1 \\
\mathrm{~h}=1 & \text { for } \mathrm{v} \leq 0.5
\end{array}
$$

Where

$$
\begin{array}{ll}
n=0.2\left(4-\frac{B}{L}\right)(1-0.02 \kappa) & \text { for } \theta=0^{\circ} \\
n=0.15\left(1+3 \frac{B}{L}\right)(1-0.02 \kappa) & \text { for } \theta=90^{\circ}
\end{array}
$$

The above equations indicate that the effect of degree of soil heterogeneity is independent of foundation aspect ratio and the plane of loading for the normalised V-H failure envelopes. 
The quality of the curve fitting is shown in Figure 10 and Figure 11 for normalised $V-\mathrm{H}_{\mathrm{x}}$ and V-Hy failure envelopes, respectively.

\subsection{Combined V-M capacity}

The normalised V-M failure envelopes might be described by a simple power law proposed by Gourvenec and Randolph (2003) for strip and circular foundations (equation(9))

$$
\mathrm{v}=(1-\mathrm{m})^{\mathrm{p}}
$$

The power $\mathrm{p}$ for rectangular foundations on homogenous soil was defined as a function of the aspect ratio B/L (Gourvenec, 2007), as equation (10)

$\left.\mathrm{p}\right|_{\kappa=0}=0.23\left[1+0.43 \frac{\mathrm{B}}{\mathrm{L}}-0.13\left(\frac{\mathrm{B}}{\mathrm{L}}\right)^{2}\right]$

where $\left.\mathrm{p}\right|_{\kappa=0}=0.23$ for strip foundations. The quadratic polynomial was established only for foundations rotating about the long axis, i.e. the $\mathrm{V}-\mathrm{M}_{\mathrm{y}}$ loading. Equation (10) is therefore only applicable for interpolating $\mathrm{p}$ within $0 \leq \mathrm{B} / \mathrm{L} \leq 1$. Feng et al. (2014) showed that the value of $\mathrm{L} / \mathrm{B}=2$ can be substituted into equation (10) to extrapolate the value of $\mathrm{p}$ for the normalised $\mathrm{V}-\mathrm{M}_{\mathrm{x}}$ failure envelopes for a mudmat with $\mathrm{B} / \mathrm{L}=0.5$. Presumably, equation (10) gives reasonable estimation of $\mathrm{p}$ for the aspect ratio up to 2. Current FE results indicate that equation (10) significantly over-predicts the normalised $\mathrm{V}-\mathrm{M}_{\mathrm{x}}$ failure envelopes for more slender mudmats of $\mathrm{B} / \mathrm{L}=0.2$ by using the value of $\mathrm{L} / \mathrm{B}=5$ to extrapolate $\mathrm{p}$. The shape effect for the case of uniform soil is then adjusted to account for a wider range of aspect ratios. In the $\mathrm{V}-\mathrm{M}_{\mathrm{y}}$ loading plane, the shape of the normalised failure envelopes might be expressed as equation (11).

$\left.\mathrm{p}\right|_{\kappa=0}=0.23\left[1+0.34 \frac{\mathrm{B}}{\mathrm{L}}-0.02\left(\frac{\mathrm{B}}{\mathrm{L}}\right)^{2}\right]$ 
The normalised $\mathrm{V}-\mathrm{M}_{\mathrm{x}}$ failure envelopes were subsequently described by substituting L/B for $\mathrm{B} / \mathrm{L}$ as

$\left.\mathrm{p}\right|_{\kappa=0}=0.23\left[1+0.34 \frac{\mathrm{L}}{\mathrm{B}}-0.02\left(\frac{\mathrm{L}}{\mathrm{B}}\right)^{2}\right]$

Following determination of shape factor for the mudmats on uniform soil, the degree of soil strength heterogeneity was then investigated. For a given aspect ratio, the shape of the normalised $\mathrm{V}-\mathrm{M}_{\mathrm{y}}$ failure envelope contracts inwards with increasing degree of soil heterogeneity and ultimately converges to a parabola, i.e. $p=0.5$, for $\kappa=20$. Taking account for the coupling effect of the aspect ratio and degree of soil heterogeneity, the value of $p$ is presented by equation (13) for describing the normalised V-M failure envelopes (Figure 12).

$\mathrm{p}=\operatorname{Min}\left(0.5,\left.\quad \mathrm{p}\right|_{\kappa=0} \times\left[1+\left(0.13-0.04 \frac{\mathrm{B}}{\mathrm{L}}\right) \kappa-0.003 \kappa^{2}\right]\right)$

For a given aspect ratio, the coupling effect becomes less significant for interaction under V$\mathrm{M}_{\mathrm{x}}$ loading, indicated by the narrower band spanned by the failure envelopes (Figure 13). Figure 13a shows that the normalised $\mathrm{V}-\mathrm{M}_{\mathrm{x}}$ failure envelopes gradually converge into a unique curve for a slender mudmat of $\mathrm{L} / \mathrm{B}=5$, irrespective of the degree of soil heterogeneity. The parabola with $\mathrm{p}=0.5$ is again employed to describe the shape of failure envelopes. The value of $\mathrm{p}$ for predicting the normalised $\mathrm{V}-\mathrm{M}_{\mathrm{x}}$ failure envelopes is then presented by equation (14) to consider the diminishing coupling effects of aspect ratios and degree of soil heterogeneity.

$\mathrm{p}=\operatorname{Min}\left(0.5,\left.\quad \mathrm{p}\right|_{\kappa=0} \times\left[1+0.09 \kappa-0.003 \kappa^{2}\right]\right)$

For all soil profiles with $\kappa<10$, the shape effect is more significant in the normalised $V-M_{x}$ loading plane than in $\mathrm{V}-\mathrm{M}_{\mathrm{y}}$. The shape of normalised V-M failure envelopes is independent of the foundation aspect ratio as the degree of soil heterogeneity $\kappa \geq 10$ (Figure 14). 


\subsection{Biaxial horizontal and moment capacity}

For surface mudmats, a horizontal sliding mechanism governs failure and the pure horizontal capacity equals the product of the mudmat bearing area, A, and soil shear strength at mudmat base level, su0, irrespective of the shape of the mudmat, soil strength heterogeneity $\kappa$ and the direction of motion of the mudmats. Therefore, the normalised $\mathrm{H}_{\mathrm{x}}-\mathrm{H}_{\mathrm{y}}$ failure envelope is theoretically circular, expressed as

$$
\left(h_{x}\right)^{2}+\left(h_{y}\right)^{2}=1
$$

The biaxial moment capacity is represented by the failure envelopes for combined $M_{y}-M_{x}$ loading (Figure 15). The normalised failure envelope of the biaxial moment loading contracts inward with increasing degree of soil strength heterogeneity. The failure envelopes span a wider band with varying soil strength heterogeneity for more slender mudmats and are more narrowly banded as the aspect ratio of the mudmat increases. For a square mudmat, the effect of the soil strength heterogeneity on the normalised shape of the $\mathrm{M}_{\mathrm{x}}-\mathrm{M}_{\mathrm{y}}$ failure envelope is negligible. The normalised $\mathrm{M}_{\mathrm{y}}-\mathrm{M}_{\mathrm{x}}$ failure envelopes was described by a general ellipse, expressed as

$$
\left(\mathrm{m}_{\mathrm{y}}\right)^{\mathrm{a}}+\left(\mathrm{m}_{\mathrm{x}}\right)^{\mathrm{b}}=1
$$

Where

$$
\mathrm{a}=0.25[\exp (-0.27 \kappa)+7]
$$

$\mathrm{b}=\mathrm{a}\left[\frac{\mathrm{B}}{\mathrm{L}}+\xi\left(1-\frac{\mathrm{B}}{\mathrm{L}}\right)\right]$

With

$\xi=1.66-0.34 \kappa^{0.5}+0.04 \kappa$

The failure envelopes derived from the proposed expression are plotted in Figure 15 together with the FE results. Figure 16 shows that the normalised $M_{y}-M_{x}$ failure envelope for a square 
mudmat falls innermost for the cases of low soil strength heterogeneity. As the degree of soil heterogeneity increases beyond 5, the shape effect is insignificant.

\subsection{General combined V-M-H capacity}

The shape of the normalised $\mathrm{M}-\mathrm{H}$ failure envelope is affected by foundation aspect ratio, the degree of soil heterogeneity and the direction of the resultant horizontal loading. The normalised $\mathrm{M}-\mathrm{H}$ failure envelopes are insensitive of the aspect ratio of the mudmats for all degrees of soil heterogeneity if the horizontal load acts along the short axis, i.e. $\theta=0^{\circ}$. For the case when the horizontal load is applied along the long axis, i.e. $\theta=90^{\circ}$ (the commonplace in field), the normalised M-H failure envelopes span a wider band for uniform soil, contracting inward on the quadrant of $+\mathrm{H}+\mathrm{M}$ (defined as left to right and clockwise) and expanding outward on the quadrant of $-\mathrm{H}+\mathrm{M}$ as the aspect ratio reduces. The band width diminishes as the degree of soil strength heterogeneity increases (Figure 17). For a given aspect ratio, the M-H failure envelopes contract inward over the quadrant of $+\mathrm{H}+\mathrm{M}$ and expand outward over the quadrant of $-\mathrm{H}+\mathrm{M}$ with increasing degree of soil heterogeneity, leading to decreased asymmetry (Figure 18).

Undrained failure envelopes of rectangular mudmats under general H-M loading might be described by equation (19)

$\left(\frac{\mathrm{M}}{\mathrm{M}_{\mathrm{ult}}} \frac{\mathrm{M}}{|\mathrm{M}|}\right)^{\mathrm{q}}\left[1-\alpha \frac{\mathrm{H}}{\mathrm{H}_{\mathrm{ult}}} \frac{\mathrm{M}}{|\mathrm{M}|}+\beta\left(\frac{\mathrm{H}}{\mathrm{H}_{\mathrm{ult}}}\right)^{2}\right]+\left(\frac{\mathrm{H}}{\mathrm{H}_{\mathrm{ult}}}\right)^{2}=1$

Where, the power $\mathrm{q}$, the coefficients $\alpha$ and $\beta$ are defined as functions of the foundation aspect ratio, the degree of soil strength heterogeneity and the direction of the resultant horizontal load. They may be approximated as

$$
\begin{aligned}
& q=3(1+0.1 \kappa) \\
& \alpha=\operatorname{Min}(0.9,1.25-0.17 \chi) \cdot \operatorname{Max}\{0,1+\kappa \cdot[0.11-0.08 \operatorname{Max}(1, \chi)]\} \\
& \beta=0.03 \kappa \cdot \operatorname{Min}(3,5-\chi)
\end{aligned}
$$


where $\chi=(B / L)^{1-4 \theta / \pi}$.

Vertical load due to the self-weight of the mudmat and the structure is often less than $30 \%$ of the vertical capacity. By taking advantage of the small proportion for the vertical load mobilisation, equation (19) can be adjusted by substituting $H_{\max }$ and $M_{\max }$ for $H_{u l t}$ and $M_{\text {ult }}$ as below to describe the general V-M-H failure envelopes.

$$
\left(\frac{\mathrm{M}}{\mathrm{M}_{\max }} \frac{\mathrm{M}}{|\mathrm{M}|}\right)^{\mathrm{q}}\left[1-\alpha \frac{\mathrm{H}}{\mathrm{H}_{\max }} \frac{\mathrm{M}}{|\mathrm{M}|}+\beta\left(\frac{\mathrm{H}}{\mathrm{H}_{\max }}\right)^{2}\right]+\left(\frac{\mathrm{H}}{\mathrm{H}_{\max }}\right)^{2}=1
$$

where, $\mathrm{H}_{\max }$ and $\mathrm{M}_{\max }$ are the maximum horizontal and moment load, which are determined respectively by equations (7) and (9) for given vertical load mobilisation v $=\mathrm{V} / \mathrm{V}_{\mathrm{ult}}$. Examples of the V-M-H failure envelopes in the normalised loading space are shown in Figure 19 for the case of $\theta=90^{\circ}$ and $\kappa=5$ at $\mathrm{v}=0.25$. Reasonable agreements are achieved between the $\mathrm{FE}$ results and the predictions by equation (21).

\subsection{Effect of torsion}

In this paper, the failure envelopes for the $\mathrm{V}-\mathrm{M}-\mathrm{H}$ capacity are presented, considering horizontal load and moment in both orthogonal directions, but not explicitly presenting failure envelopes of horizontal load-torsion and moment-torsion interaction. The effect of the torsion for mudmats with varying aspect ratio can be evaluated by scaling the normalised V-M-H failure envelope proportionally using the maximum available horizontal and moment capacity for given torsion mobilisation as proposed in Feng et al. (2014) with scaling factors for mudmats of varying aspect ratio presented in Feng et al. (2016) for horizontal load-torsion interaction, and Abyaneh et al. (2015) for moment-torsion interaction. The strategy is guaranteed by that the influence of torsion was most significant where sliding failure occurs and least significant where deep bearing failure occurs. The mudmat might be assumed to be founded on a soil with artificially reduced shear strength only at base (sliding) level. Even though the horizontal sliding resistance decreased by as a result of the torsion, the H-M 
interaction mechanism was only slightly affected. Therefore, the shape of the V-M-H failure envelopes for varying torsion was remains similar and can be predicted by scaling the normalised V-M-H failure envelope proportionally using the maximum available horizontal and moment capacity for given torsion mobilisation.

\section{CALCULATION PROCEDURE}

The calculation procedure for predicting the undrained multi-directional ultimate limit state of mudmats for the range of foundation aspect ratio and soil strength heterogeneity covered in this study includes:

Step 1: For given mudmat geometry and soil strength profile, evaluate the width-to-length aspect ratio $B / L$ and degree of soil heterogeneity $\kappa=\rho B / s_{u 0}$.

Step 2: Evaluate the uniaxial capacity for pure vertical (equation (3)), horizontal (equation (4)) and moment loading (equations (5) and (6)).

Step 3: Reduce the ultimate horizontal and moment capacity to the maximum available values, according to the vertical load mobilisation ( $\left.\mathrm{v}=\mathrm{V} / \mathrm{V}_{\mathrm{ult}}\right)$. Equations (7) and (8) are used to calculate the maximum available horizontal load, and equations (9), (13) and (14) for the maximum available moment.

Step 4: For given angle of horizontal load $\theta$, assess the corresponding ultimate horizontal capacity (equation (15)), and similarly for the ultimate moment capacity (equations (16) to (18)). (Modify for torsional loading if applicable).

Step 5: Evaluate extent to which applied (design) loading falls within M-H failure envelope (equation (21)), and thus safety factors on self-weight $\mathrm{V}$, live loading $\mathrm{H}, \mathrm{M}$, or material strength $\mathrm{s}_{\mathrm{u} 0}$.

This procedure, in conjunction with the equations presented in this paper, can be used to develop an automated calculation tool for instantaneous generation of failure envelopes for 
given foundation and soil conditions and automatic iteration to optimise mudmat size for given loading and material factor.

\section{CONCLUDING REMARKS}

The undrained multi-directional capacity of rectangular subsea mudmats on soil with linearly increasing strength with depth has been presented as failure envelopes. The coupling effects of the width-to-length aspect ratio of the mudmats and the degree of the soil strength heterogeneity have been systematically investigated. Algebraic expressions are presented to describe ultimate uniaxial limit states and normalised failure envelopes as a function of foundation width-to-length aspect ratio, soil strength heterogeneity and loading direction (relative to the orthogonal axes of the foundation). The expressions can be programmed into a calculation software to enable instantaneous generation of failure envelopes for given foundation and soil conditions and automatic iteration to optimize mudmat size for given loading and material factor.

The results have shown that ultimate uniaxial capacities and the shape of the normalised failure envelope are dependent on the coupled interaction of the width-to-length aspect ratio of the mudmats and the degree of the soil strength heterogeneity. Foundation aspect ratio was shown to have limited effect on the shape of the normalised failure envelopes for cases of high soil strength heterogeneity irrespective of loading direction, but became significant for the common loading scenario of horizontal loading along the long, y-axis, with corresponding moment about the shorter, x-axis, particularly for cases of low soil strength heterogeneity.

The results demonstrate the complex coupling of foundation aspect ratio and soil strength heterogeneity in prediction of undrained capacity of mudmats under multi-directional loading.

The expressions and methodology presented in this paper enable prediction of mudmat capacity for given foundation and soil conditions, or optimization of mudmat size for given 
loading and material factor, for multi-directional loading, as a function of mudmat width-tolength aspect ratio and degree of the soil strength heterogeneity.

\section{ACKNOWLEDGEMENTS}

This work forms part of the activities of the Centre for Offshore Foundation Systems (COFS), established in 1997 under the Australian Research Council's Special Research Centres Program, and supported as a node of the Australian Research Council's Centre of Excellence for Geotechnical Science and Engineering, and through the Fugro Chair in Geotechnics, the Lloyd's Register Foundation Chair and Centre of Excellence in Offshore Foundations and the Shell EMI Chair in Offshore Engineering. The first author is supported by ARC grant DP140100684. Lloyd's Register Foundation helps to protect life and property by supporting engineering-related education, public engagement and the application of research. The second author is supported through ARC grant CE110001009. The third author worked on the research project presented in this paper while a visiting scholar at COFS, supported through a China Scholarship Council (CSC) scholarship and the Australia-China Natural Gas Technology Partnership Fund Top-Up Scholarship. The work presented in this paper is supported through ARC grant DP140100684. This support is gratefully acknowledged.

\section{APPENDIX: VERTICAL AND MOMENT CAPACITY OF RECTANGULAR FOUNDATIONS FOR CASES OF DIFFERENT ASPECT RATIOS AND DIFFERENT SOIL PROFILES}

Supplementary analyses on the pure uniaxial capacities were carried out for two intermediate aspect ratios $(\mathrm{B} / \mathrm{L}=0.25$ and 0.625$)$ and various soil strength profiles $(\kappa=0,0.5,4,8,12,15$ and 20). The FE results are presented together with the proposed algebraic expressions derived from the study presented in the main body of this paper, indicating the applicability of the formulas for other foundation aspect ratios and soil strength profiles beside those selected for the main study as presented in this paper. 


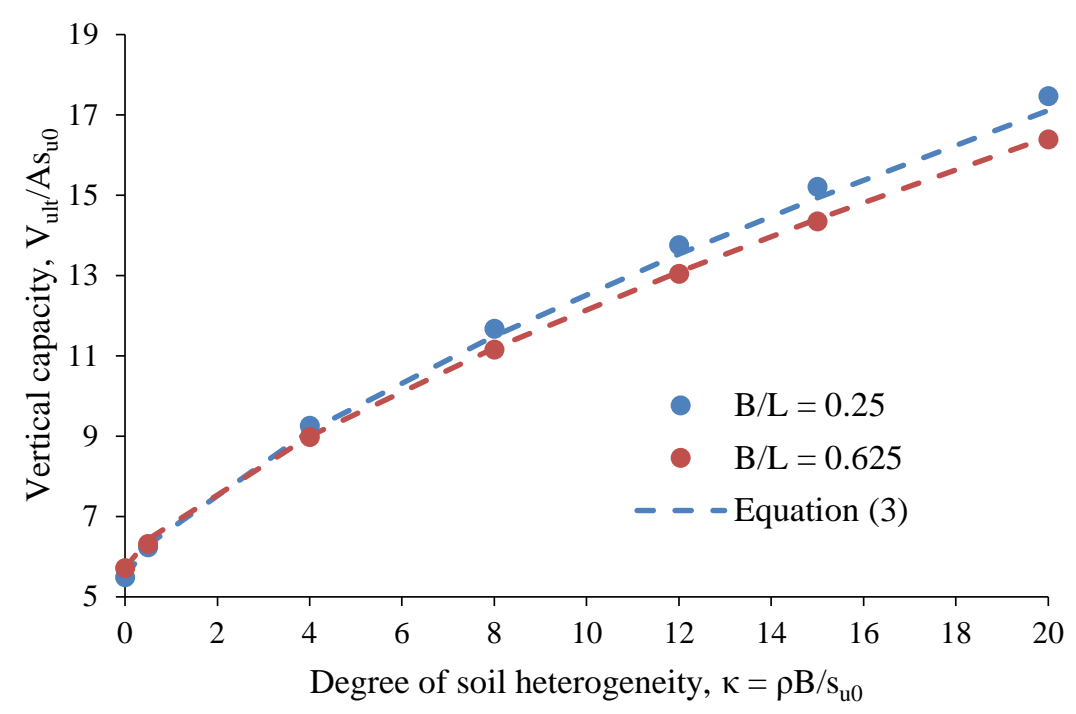

Figure A1. Vertical bearing capacity

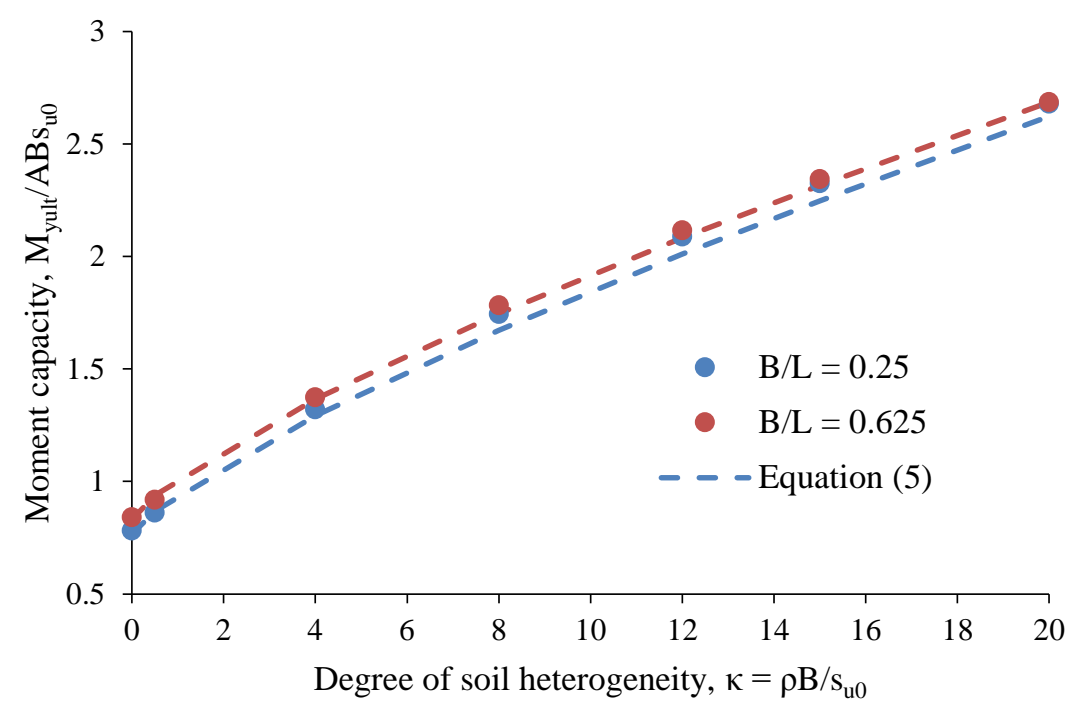

Figure A2. Moment capacity about y-axis 


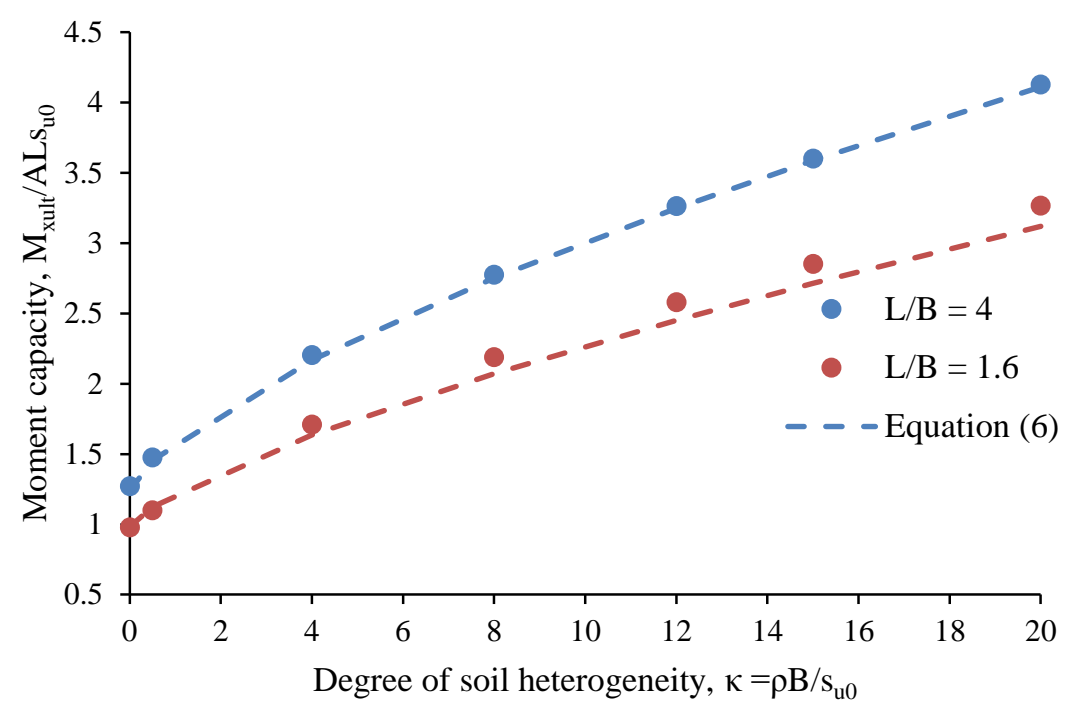

Figure A3. Moment capacity about x-axis

\section{REFERENCES}

Abyaneh, S.D., Ojo, A., Maconochie, A., Haghighi, A., 2015. The undrained bearing capacity of shallow foundations subjected to three-dimensional loading including torsion. In: Proc of the $25^{\text {th }}$ Int Offshore Polar Eng Conf. International Society of Offshore and Polar Engineers, Hawaii, USA, pp. 668-674.

Bransby, M.F., Randolph, M.F., 1998. Combined loading of skirted foundations. Géotechnique 48 (5), 637-655.

Dassault Systèmes, 2011. Abaqus analysis users' manual. Simulia Corp, Providence, RI, USA.

Davis, E.H., Booker, J.R., 1973. The effect of increasing strength with depth on the bearing capacity of clays. Géotechnique 23 (4), 551-563.

Feng, X., Randolph, M., Gourvenec, S., 2016. An analytical solution for the undrained horizontal-torsional resistance of mudmats. Géotechnique, In Press.

Feng, X., Randolph, M.F., Gourvenec, S., Wallerand, R., 2014. Design approach for rectangular mudmats under fully three-dimensional loading. Géotechnique 64 (1), 51-63.

Fontaine, E., Dilosquer, S., 2014. Post-installed Mudmat. In: Proc of Offshore Technology Conference. Offshore Technology Conference, Houston, Texas, pp. OTC-25124-MS.

Gourvenec, S., 2007. Shape effects on the capacity of rectangular footings under general loading. Géotechnique 57 (8), 637-646.

Gourvenec, S., Randolph, M., 2003. Effect of strength non-homogeneity on the shape of failure envelopes for combined loading of strip and circular foundations on clay. Géotechnique 53 (6), 575-586.

Gourvenec, S., Randolph, M., Kingsnorth, O., 2006. Undrained bearing capacity of square and rectangular footings. International Journal of Geomechanics 6 (3), 147-157. 
Green, A., 1954. The plastic yielding of metal junctions due to combined shear and pressure. Journal of the Mechanics and Physics of Solids 2 (3), 197-211.

ISO, 2003. Petroleum and natural gas industries specific requirements for Offshore Structures - Part 4: Geotechnical and foundation design considerations - $1^{\text {st }}$ Eidition. International Standards Organisation, Geneva.

Kusakabe, O., Suzuki, H., Nakase, A., 1986. An upper bound calculation on bearing capacity of a circular footing on a non-homogeneous clay. Soils and Foundations 26 (3), 143-148.

Lyamin, A.V., Sloan, S.W., 2000. Rigorous lower bound solutions for the bearing capacity of rectangular foundations. In: Proc of ISRM International Symposium. International Society for Rock Mechanics, pp. ISRM-IS-2000-2200.

Martin, C.M., Dunne, H.P., Wallerand, R., Brown, N., 2015. Three-dimensional limit analysis of rectangular mudmat foundations. In: Proc of the $3^{\text {rd }}$ Int. Symp. on Front. in Offshore Geotech. (ISFOG 2015). London, UK: CRC Press, Oslo, Norway, pp. 789-794.

Merifield, R., Nguyen, V., 2006. Two-and three-dimensional bearing-capacity solutions for footings on two-layered clays. Geomechanics and Geoengineering: An International Journal 1 (2), 151-162.

Michalowski, R.L., 2001. Upper-bound load estimates on square and rectangular footings. Géotechnique 51 (9), 787-798.

Prandtl, L., 1921. Hauptaufsätze: Über die eindringungsfestigkeit (härte) plastischer baustoffe und die festigkeit von schneiden. Zeit. Angew. Math. Mech. 1 (1), 15-20.

Randolph, M., Puzrin, A., 2003. Upper bound limit analysis of circular foundations on clay under general loading. Géotechnique 53 (9), 785-796.

Salgado, R., Lyamin, A.V., Sloan, S.W., Yu, H.S., 2004. Two- and three-dimensional bearing capacity of foundations in clay. Géotechnique 54 (5), 297-306.

Shen, Z., Feng, X., Gouvenec, S., 2016. Effect of interface condition on the undrained capacity of subsea mudmats under six-degree-of-freedom loading. Géotechnique, In Press.

Skempton, A., 1951. The bearing capacity of clays. In: Proc of Building and Research Congress, London, UK, pp. 180-189.

Taiebat, H., Carter, J., 2000. Numerical studies of the bearing capacity of shallow foundations on cohesive soil subjected to combined loading. Géotechnique 50 (4), 409-418.

Taiebat, H., Carter, J., 2010. A failure surface for circular footings on cohesive soils. Géotechnique 60 (4), 265-273.

Tan, F.S.C. 1990. Centrifuge and theoretical modelling of conical footings on sand. PhD Thesis, Cambridge University.

Tani, K., Craig, W.H., 1995. Bearing capacity of circular foundations on soft clay of strength increasing with depth. Soils and Foundations 35 (4), 21-35.

Terzaghi, K., 1943. Theoretical Soil Mechanics. John Wiley \& Sons, New York.

Zhu, M., Michalowski, R.L., 2005. Shape factors for limit loads on square and rectangular footings. Journal of Geotechnical and Geoenvironmental Engineering 131 (2), 223-231. 


\section{TABLE CAPTIONS}

Table 1 Summary of notation for loads

\begin{tabular}{|c|c|c|c|}
\hline & Vertical & Horizontal & Moment \\
\hline Load & $\mathrm{V}$ & $\mathrm{H}_{\mathrm{x}}, \mathrm{H}_{\mathrm{y}}, \mathrm{H}$ & $\mathrm{M}_{\mathrm{x}}, \mathrm{M}_{\mathrm{y}}, \mathrm{M}$ \\
\hline Ultimate load & $\mathrm{V}_{\text {ult }}$ & $\mathrm{H}_{\text {xult }}, \mathrm{H}_{\text {yult }}, \mathrm{H}_{\text {ult }}$ & $\mathrm{M}_{\text {xult }}, \mathrm{M}_{\text {yult }}, \mathrm{M}_{\text {ult }}$ \\
\hline Dimensionless load & $\mathrm{V} / \mathrm{As}_{\mathrm{u} 0}$ & $\mathrm{H}_{\mathrm{x}} / \mathrm{As}_{\mathrm{u} 0}$ & $\mathrm{M}_{\mathrm{x}} / \mathrm{ALs}_{\mathrm{u} 0}$ \\
\hline & & $\mathrm{H}_{\mathrm{y}} / \mathrm{As}_{\mathrm{u} 0}$ & $\mathrm{M}_{\mathrm{y}} / \mathrm{ABs}_{\mathrm{u} 0}$ \\
\hline Dimensionless ultimate load & $\mathrm{V}_{\mathrm{ult}} / \mathrm{As}_{\mathrm{u} 0}$ & $\mathrm{H}_{\mathrm{xult}} / \mathrm{As} \mathrm{u} 0$ & $\mathrm{M}_{\mathrm{xult}} / \mathrm{ALs}_{\mathrm{u} 0}$ \\
\hline & & $\mathrm{H}_{\text {yult }} / \mathrm{As}_{\mathrm{u} 0}$ & $\mathrm{M}_{\mathrm{yult}} / \mathrm{ABs}_{\mathrm{u} 0}$ \\
\hline Normalised load & $\mathrm{V} / \mathrm{V}_{\text {ult }}$ & $\begin{array}{l}\mathrm{h}_{\mathrm{x}}=\mathrm{H}_{\mathrm{x}} / \mathrm{H}_{\mathrm{xult}} \\
\mathrm{h}_{\mathrm{y}}=\mathrm{H}_{\mathrm{y}} / \mathrm{H}_{\text {yult }} \\
\mathrm{h}=\mathrm{H} / \mathrm{H}_{\mathrm{ult}}\end{array}$ & $\begin{array}{l}m_{x}=M_{x} / M_{x u l t} \\
m_{y}=M_{y} / M_{y u l t} \\
m=M / M_{u l t}\end{array}$ \\
\hline
\end{tabular}

Table 2 Parameters defining the soil undrained shear strength profile

\begin{tabular}{l|l|l}
\hline $\begin{array}{l}\text { Degree of soil strength } \\
\text { heterogeneity } \kappa=\rho \mathrm{B} / \mathrm{su0},[-]\end{array}$ & $\begin{array}{l}\text { Soil undrained shear } \\
\text { strength gradient } \rho, \\
{[\mathrm{kPa} / \mathrm{m}]}\end{array}$ & $\begin{array}{l}\text { Undrained shear strength at } \\
\text { mudmat base level su0, [kPa] }\end{array}$ \\
\hline 0 & 0 & 5.0 \\
2 & 1.0 & 2.5 \\
5 & 1.0 & 1.0 \\
10 & 1.0 & 0.5 \\
20 & 1.0 & 0.25 \\
\hline
\end{tabular}

Table 3 Input parameters and calculated pure uniaxial capacities for given degree of soil strength heterogeneity

\begin{tabular}{l|l|l|l|l|l|l}
\hline$\kappa=\rho \mathrm{B} / \mathrm{s}_{\mathrm{u} 0},[-$ & $\mathrm{B},[\mathrm{m}]$ & $\rho$, & $\mathrm{S}_{\mathrm{u} 0}$, & $\begin{array}{l}\mathrm{V}_{\mathrm{ult}} / \mathrm{As}_{\mathrm{u} 0}, \\
{[-]}\end{array}$ & $\begin{array}{l}\mathrm{M}_{\mathrm{y}} / \mathrm{ABs}_{\mathrm{u} 0}, \\
{[-]}\end{array}$ & $\begin{array}{l}\mathrm{M}_{\mathrm{x}} / \mathrm{ALs}_{\mathrm{u} 0}, \\
{[-]}\end{array}$ \\
\hline \multirow{3}{*}{10} & 5 & 1.0 & 0.5 & 12.33 & 1.94 & 2.60 \\
& 5 & 0.5 & 0.25 & 12.33 & 1.94 & 2.60 \\
& 10 & 0.5 & 0.5 & 12.33 & 1.94 & 2.60 \\
\hline
\end{tabular}




\section{FIGURE CAPTIONS}

Figure 1 Nomenclature for foundation geometry, soil strength profile and general loading

Figure 2 FE mesh for rectangular foundations (half view): a) $\mathrm{B} / \mathrm{L}=0.2$; $\mathrm{b}$ ) $\mathrm{B} / \mathrm{L}=1$

Figure 3 Model validation: FE results of vertical capacity compared with available published data

Figure 4 Soil failure mechanisms under ultimate vertical load (cross-section at the central plane)

Figure 5 Shape factor of vertical capacity as a function of aspect ratio and degree of soil heterogeneity

Figure 6 Prediction of the vertical capacity of rectangular mudmats as a function of foundation aspect ratio and soil strength heterogeneity

Figure 7 Model validation: FE results of moment capacity compared with solution of limit analysis: $\mathrm{B} / \mathrm{L}=0.5$

Figure 8 Prediction of the moment capacity of rectangular mudmats as a function of foundation aspect ratio and soil strength heterogeneity

Figure 9 Normalised V-H failure envelopes for varying B/L and comparison with Green's solution

Figure 10 Prediction of the normalised $\mathrm{V}-\mathrm{H}_{\mathrm{x}}$ envelopes for varying $\mathrm{B} / \mathrm{L}$ and $\kappa$

Figure 11 Prediction of the normalised $\mathrm{V}-\mathrm{H}_{\mathrm{y}}$ envelopes for varying $\mathrm{B} / \mathrm{L}$ and $\kappa$

Figure 12 Prediction of the normalised V- $\mathrm{M}_{\mathrm{y}}$ failure envelopes for varying $\mathrm{B} / \mathrm{L}$ and $\kappa$

Figure 13 Prediction of the normalised $V-M_{x}$ failure envelopes for varying $B / L$ and $\kappa$

Figure 14 Shape effect on the normalised V-M failure envelopes

Figure 15 Normalised $\mathrm{M}_{\mathrm{y}}-\mathrm{M}_{\mathrm{x}}$ failure envelopes for varying $\mathrm{B} / \mathrm{L}$ and $\kappa$

Figure 16 Shape effect on the normalised $\mathrm{M}_{\mathrm{y}}-\mathrm{M}_{\mathrm{x}}$ failure envelopes

Figure 17 Effect of aspect ratio and angle of horizontal loading on the normalised $\mathrm{M}-\mathrm{H}$ failure envelopes

Figure 18 Effect of degree of soil heterogeneity on normalised M-H failure envelopes

Figure 19 V-M-H failure envelopes in normalised loading space 
Skirted mudmat

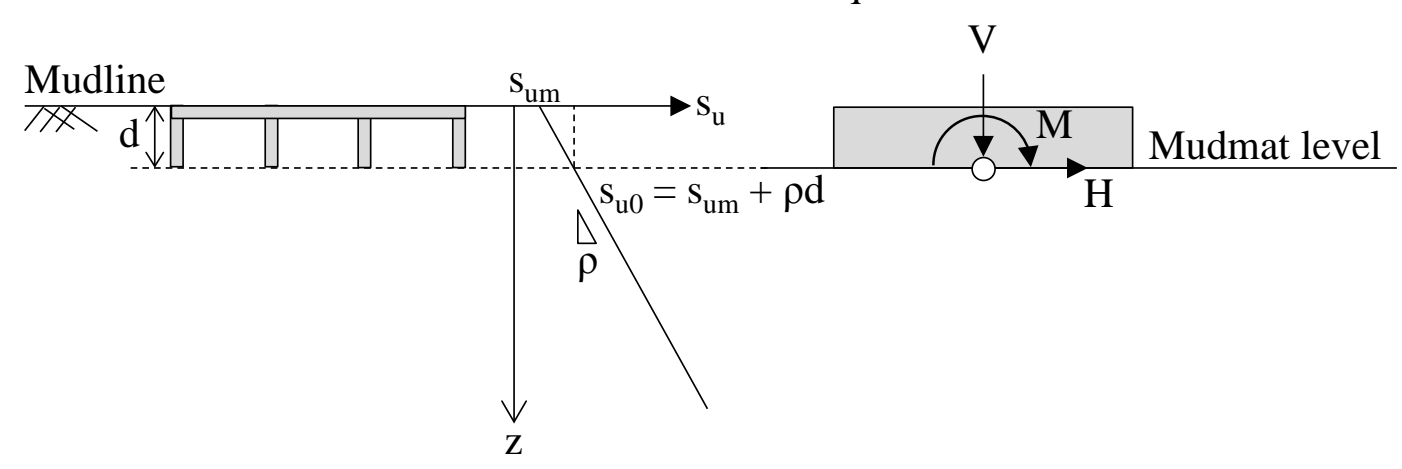

a) Foundation geometry and soil strength profile
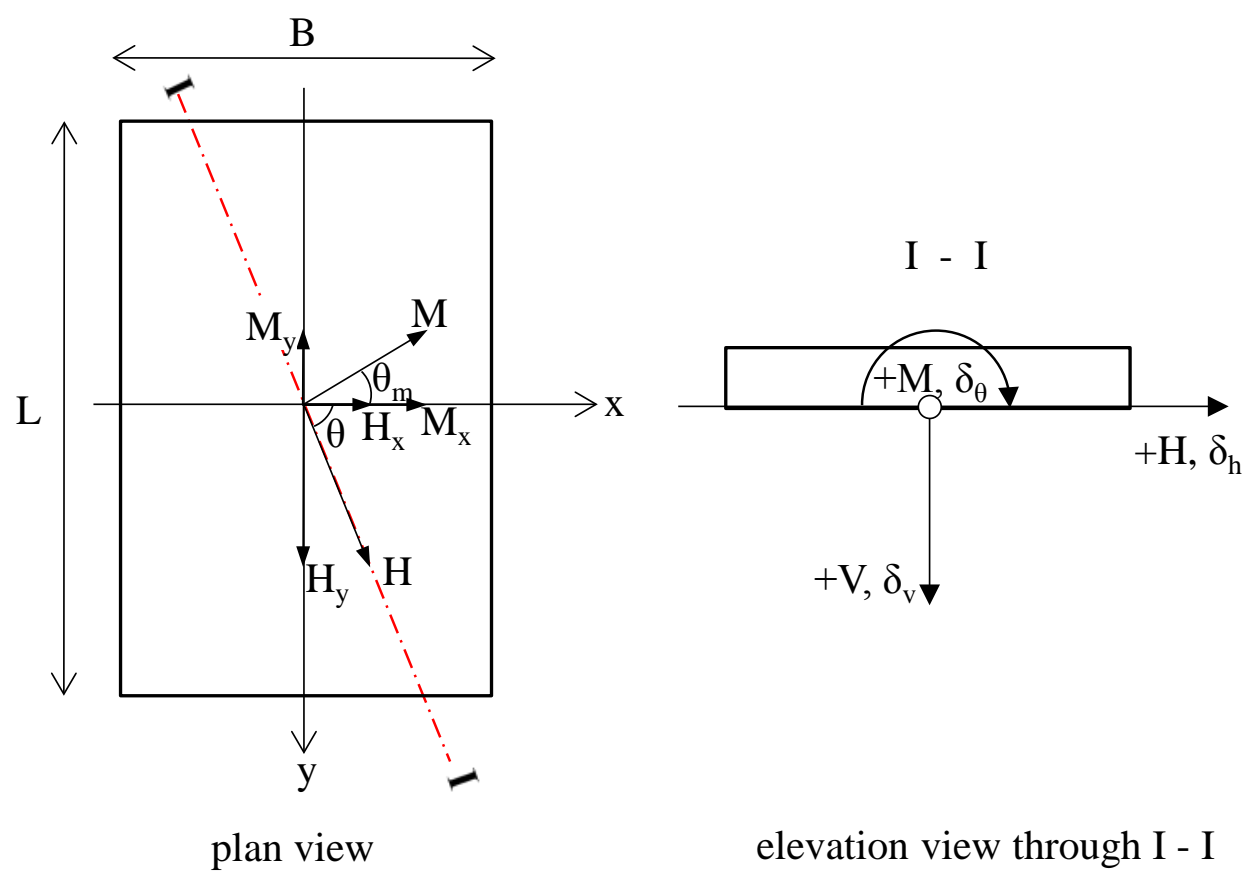

b) views of loading condition

Figure 1 Nomenclature for foundation geometry, soil strength profile and general loading 

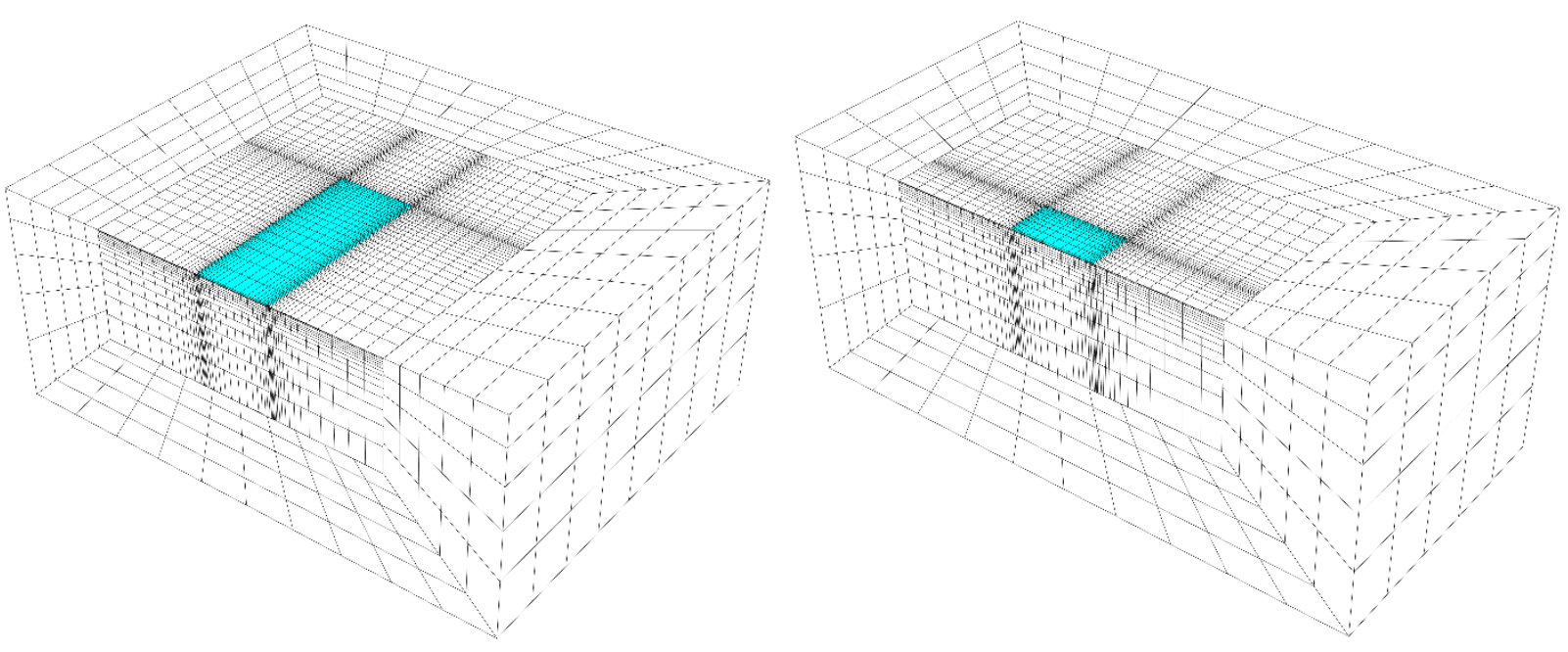

a) $\mathrm{B} / \mathrm{L}=0.2$

b) $\mathrm{B} / \mathrm{L}=1$

Figure 2 FE mesh for rectangular foundations (half view): a) $B / L=0.2 ; b) ~ B / L=1$

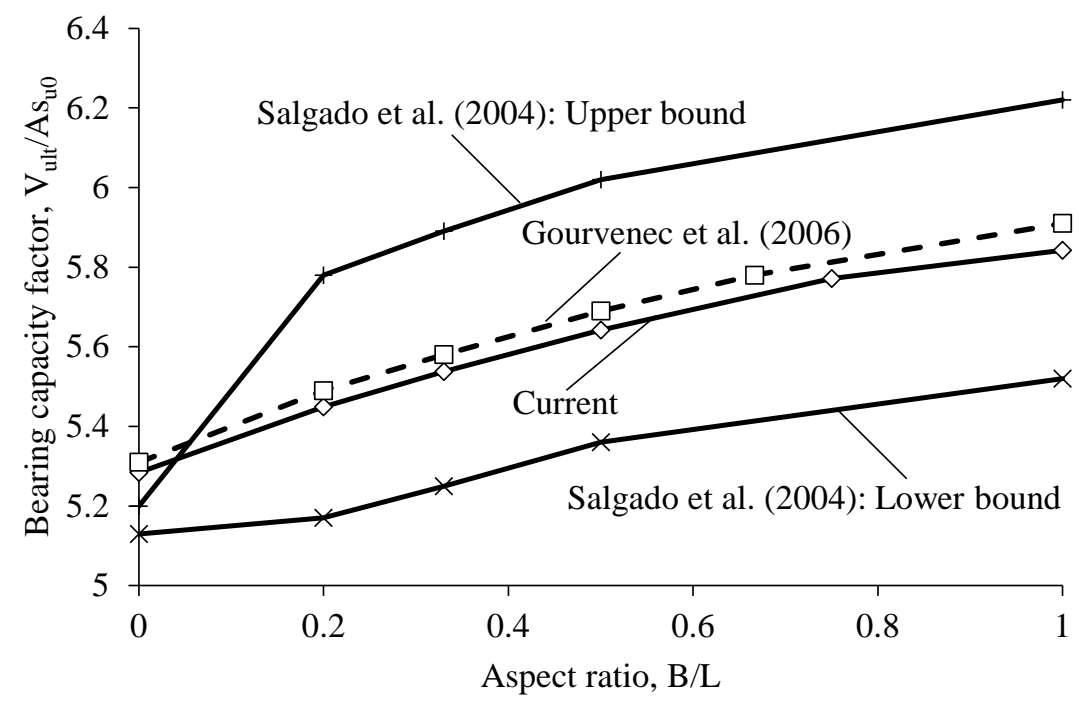

a) Vertical bearing capacity factor as function of aspect ratio: uniform soil 


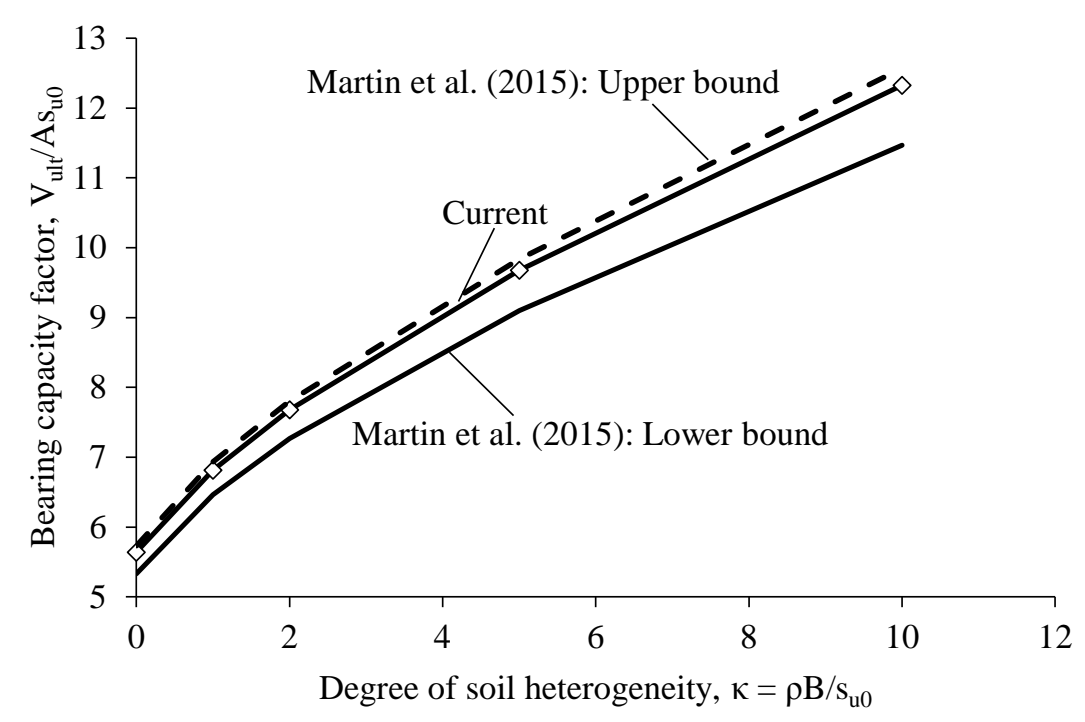

b) Vertical bearing capacity factor as function of degree of soil heterogeneity: $B / L=0.5$

Figure 3 Model validation: FE results of vertical capacity compared with available published data

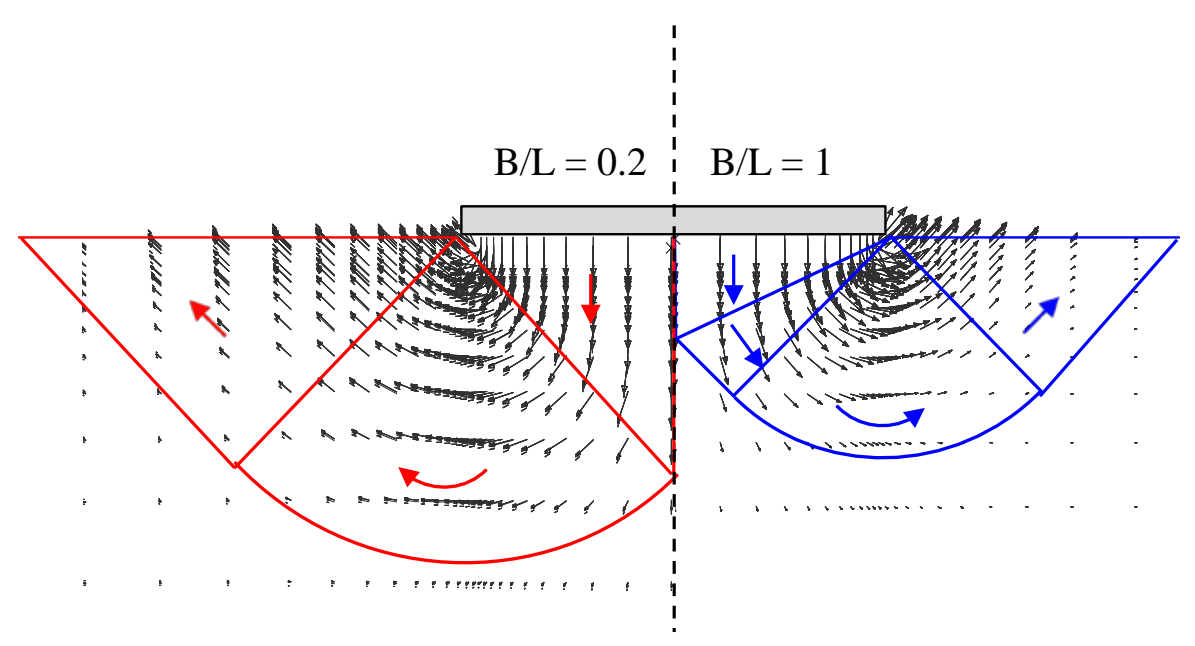

a) Prandtl mechanism (low $\kappa, \mathrm{B} / \mathrm{L} \leq 0.2$ ) and Kusakabe et al. mechanism (low $\kappa, 0.2<\mathrm{B} / \mathrm{L} \leq 1$ )

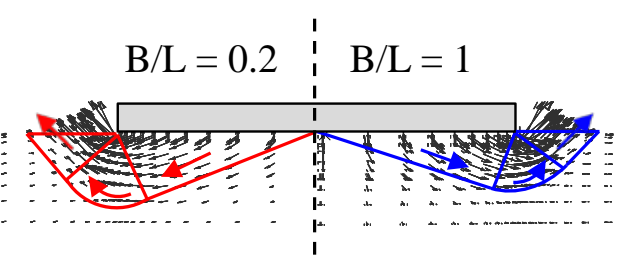

b) Bransby \& Randolph mechanism (high $\kappa$, all B/L) 
Figure 4 Soil failure mechanisms under ultimate vertical load (cross-section at the central plane)

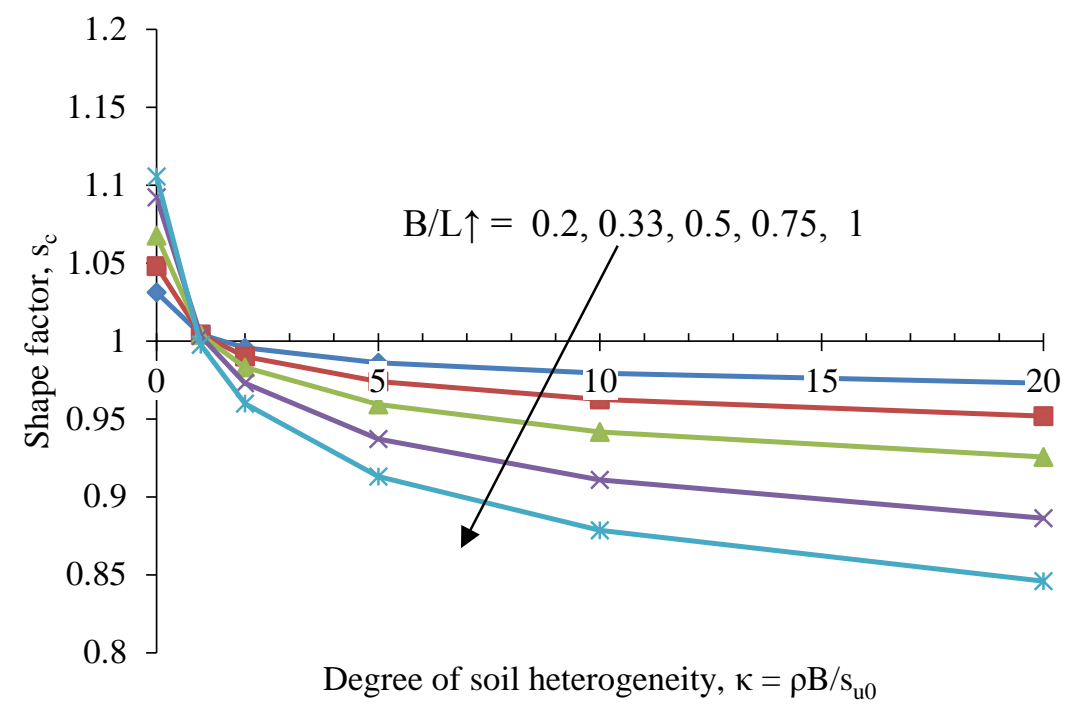

Figure 5 Shape factor of vertical capacity as a function of aspect ratio and degree of soil heterogeneity

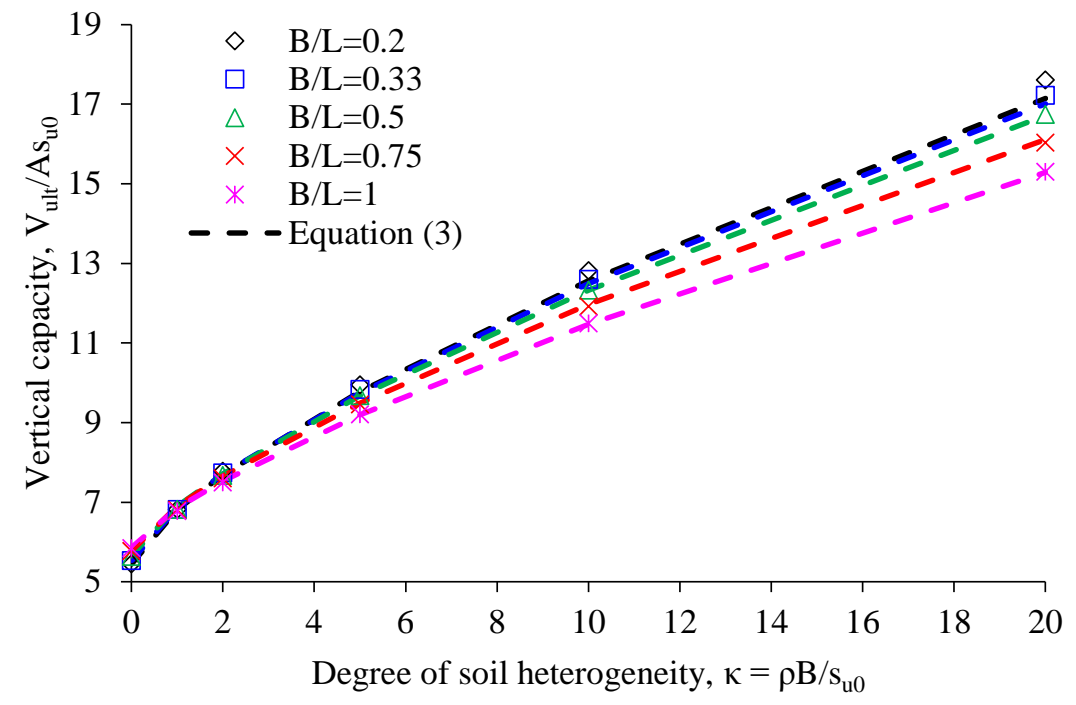

Figure 6 Prediction of the vertical capacity of rectangular mudmats as a function of foundation aspect ratio and soil strength heterogeneity 


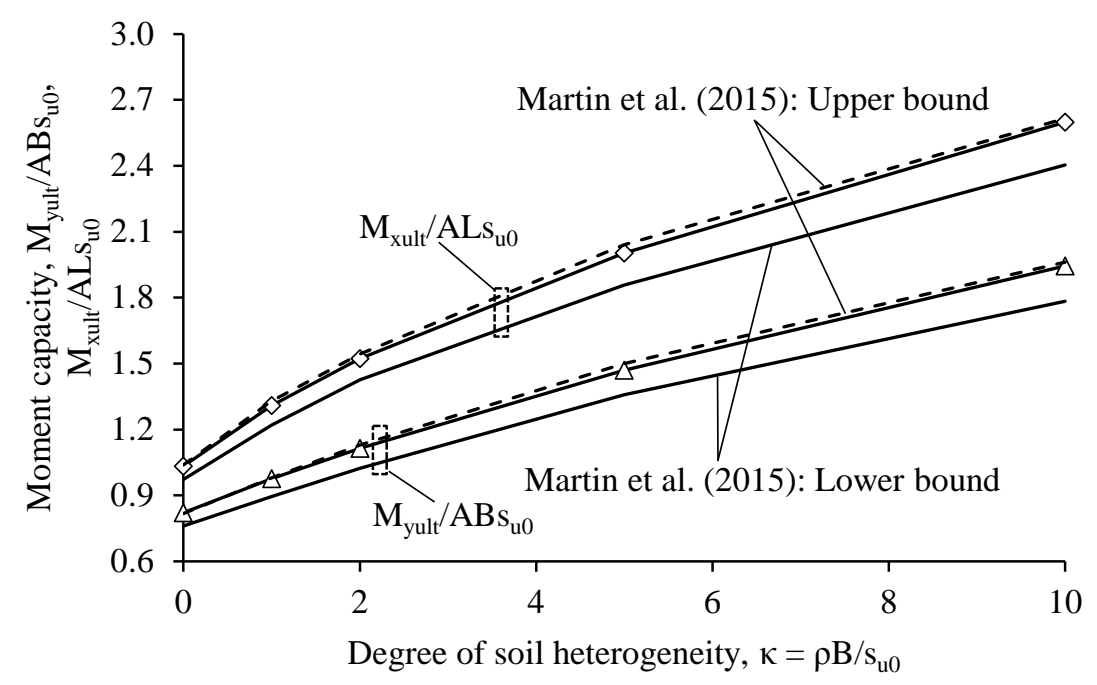

Figure 7 Model validation: FE results of moment capacity compared with solution of limit analysis: $\mathrm{B} / \mathrm{L}=0.5$

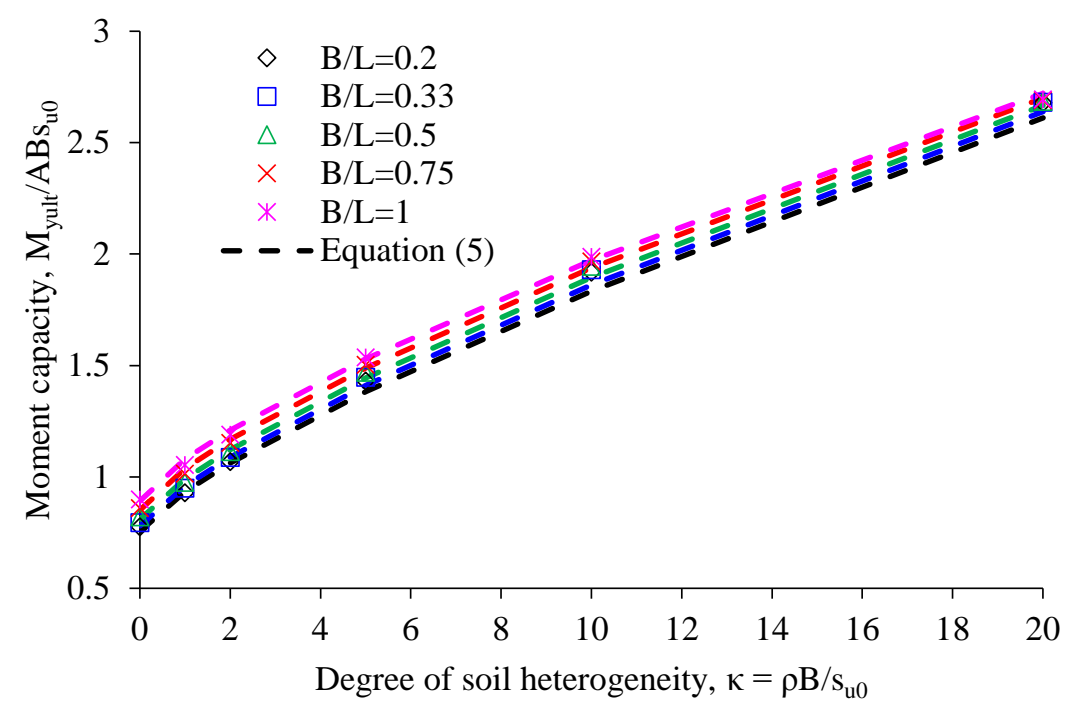

a) Moment capacity: about y- axis 


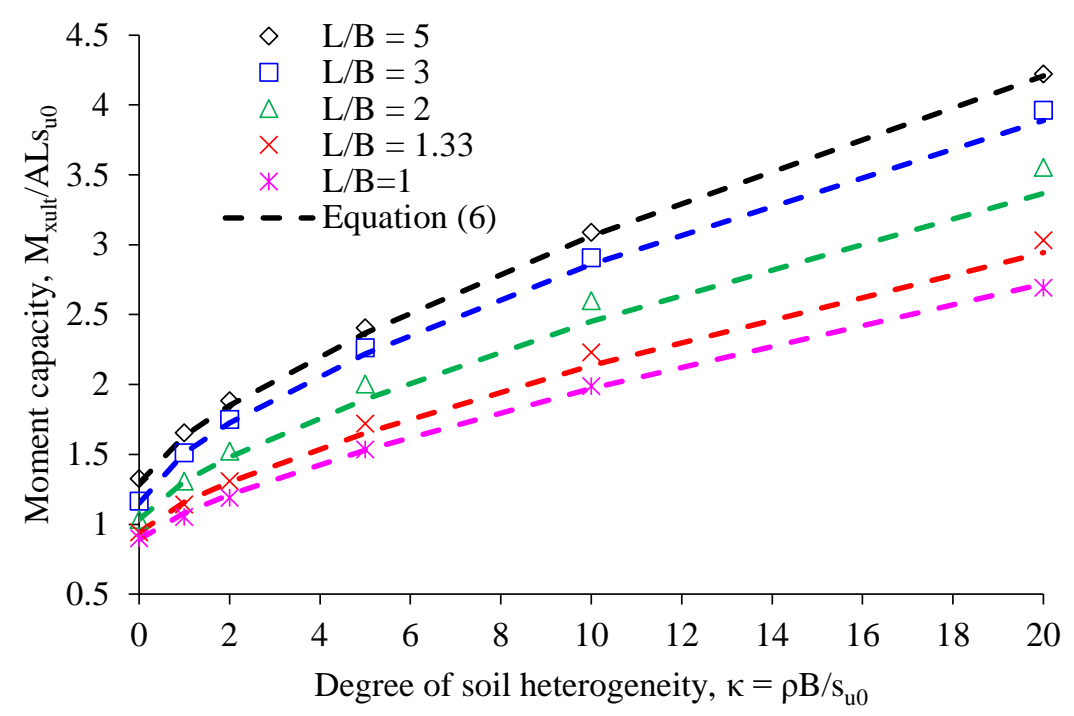

b) Moment capacity: about x-axis

Figure 8 Prediction of the moment capacity of rectangular mudmats as a function of foundation aspect ratio and soil strength heterogeneity

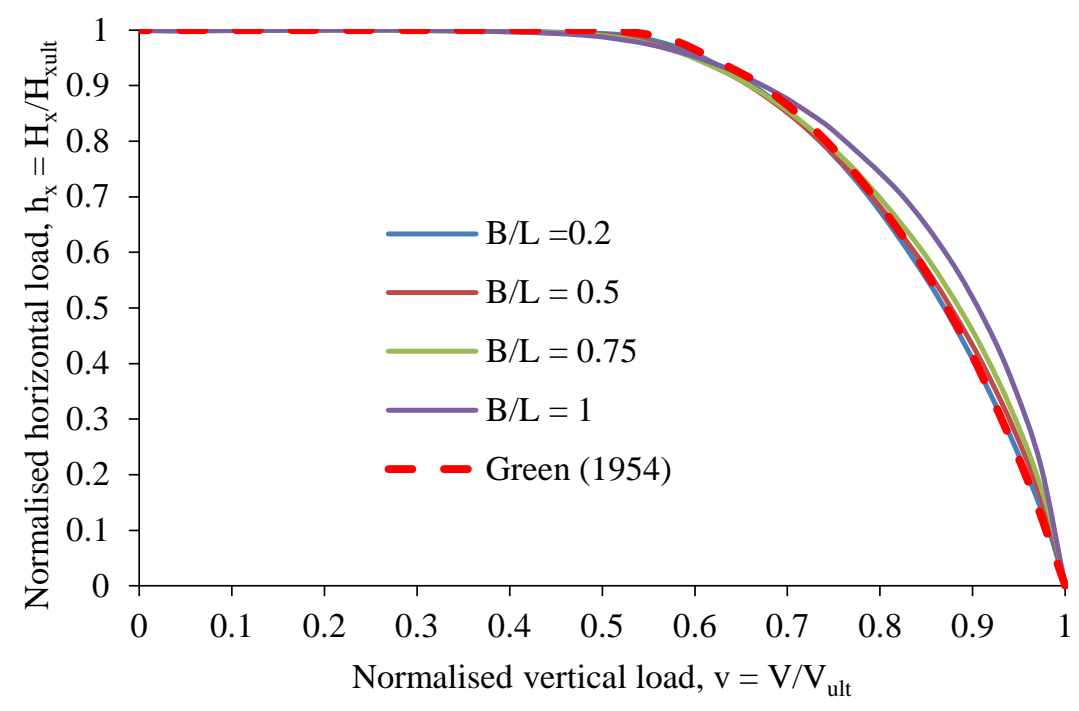

a) $\kappa=0 ; \theta=0^{\circ}$ 


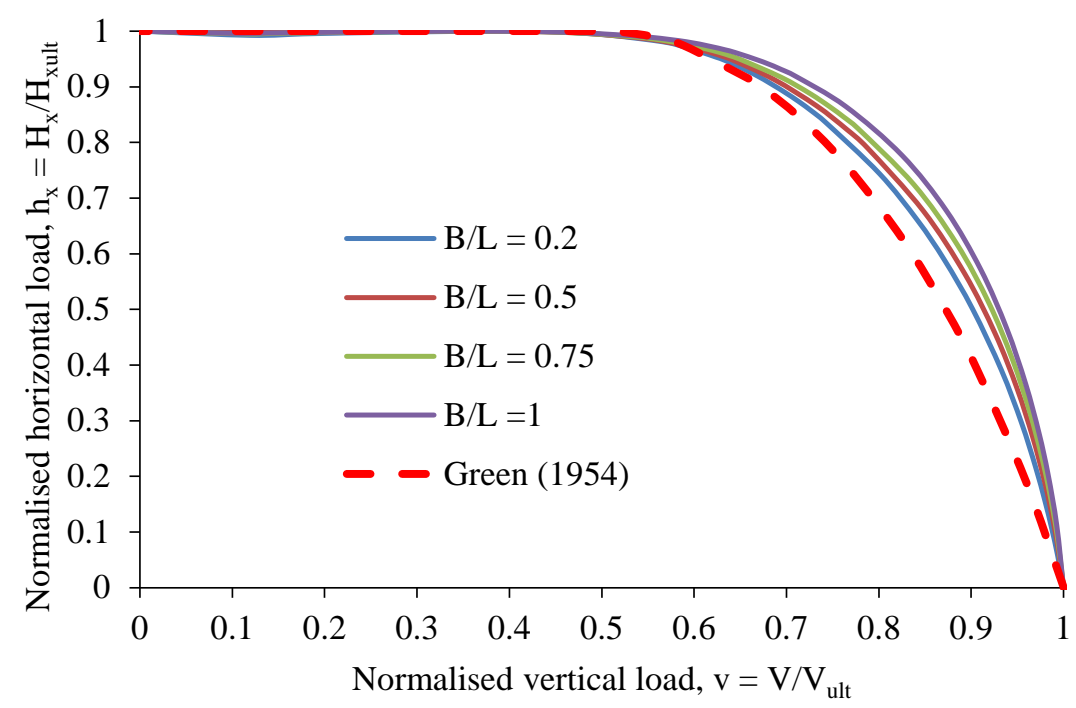

b) $\kappa=20 ; \theta=0^{\circ}$

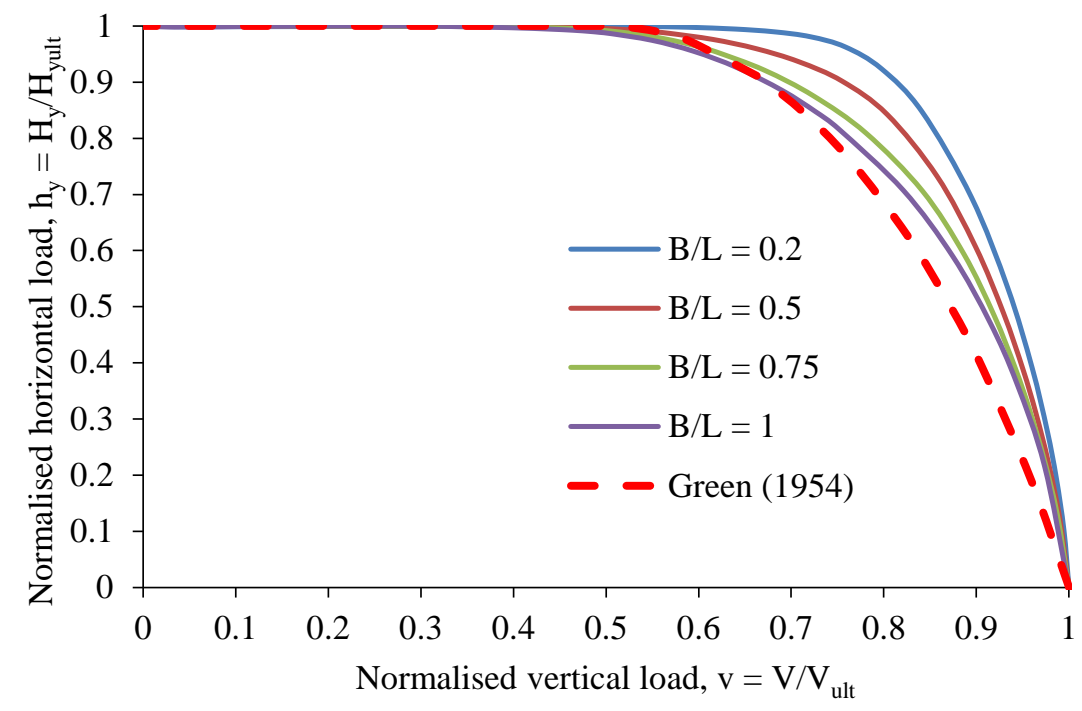

c) $\kappa=0 ; \theta=90^{\circ}$ 


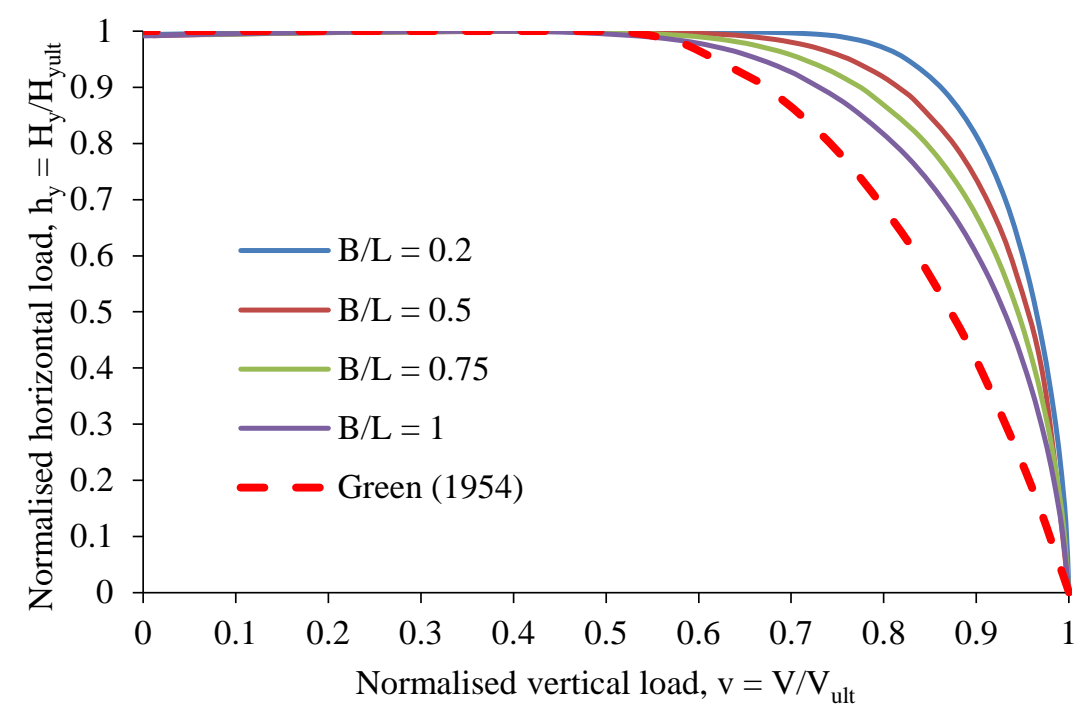

d) $\kappa=20 ; \theta=90^{\circ}$

Figure 9 Normalised V-H failure envelopes for varying B/L and comparison with Green's solution

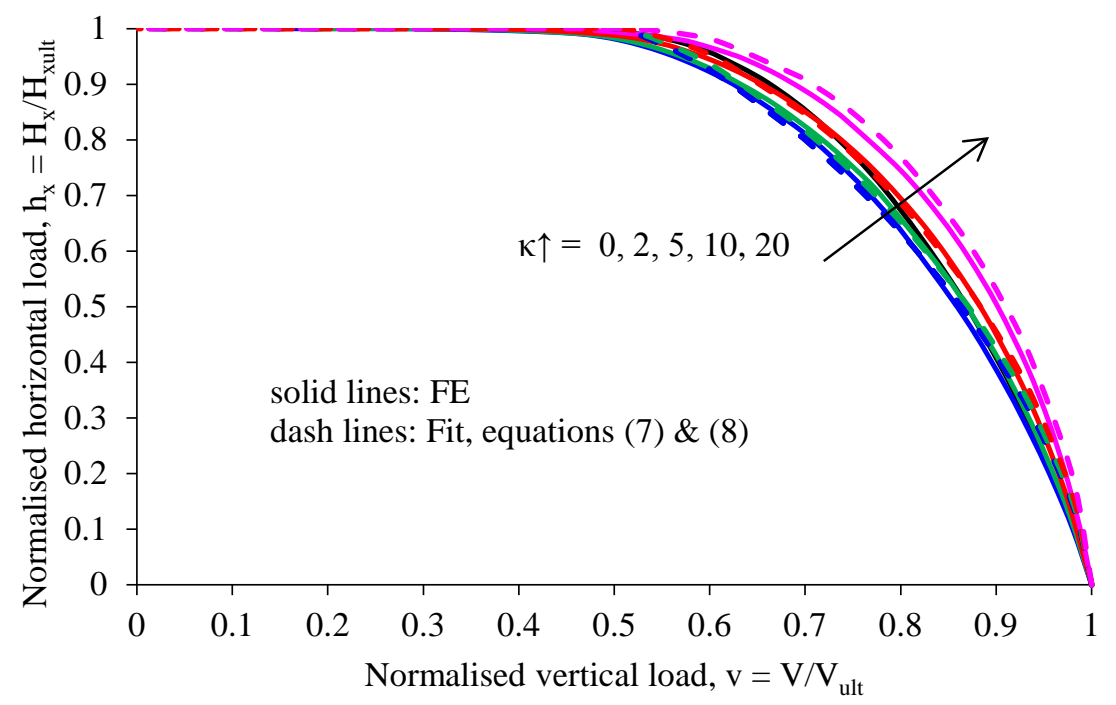

a) $\mathrm{B} / \mathrm{L}=0.2$ 


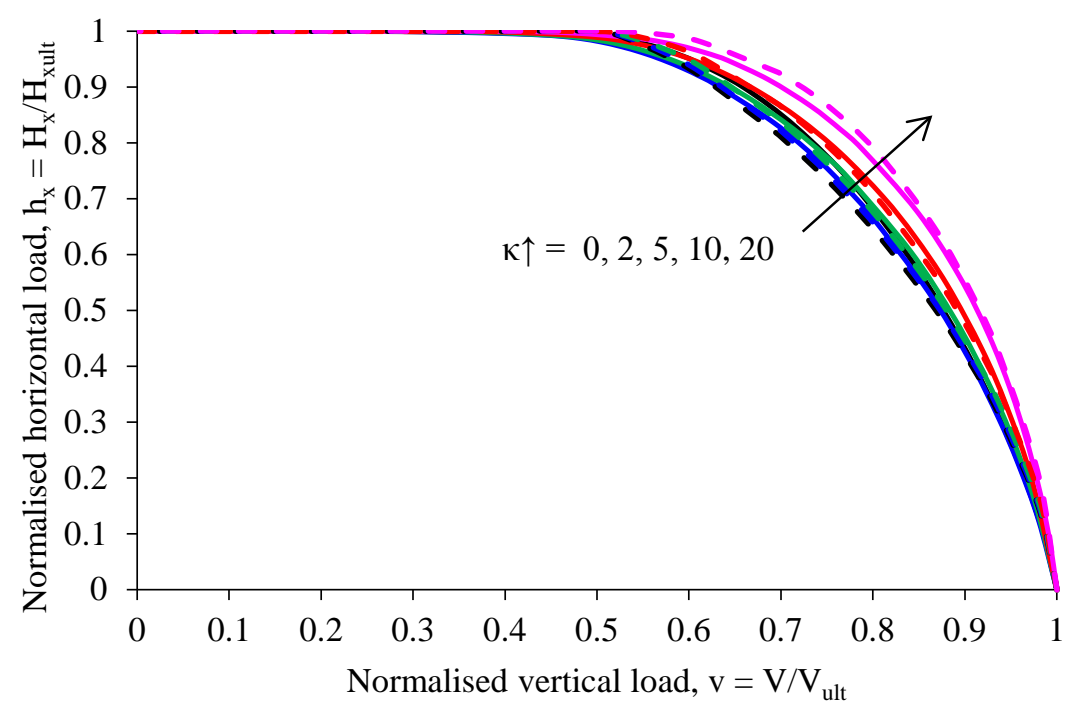

b) $\mathrm{B} / \mathrm{L}=0.5$

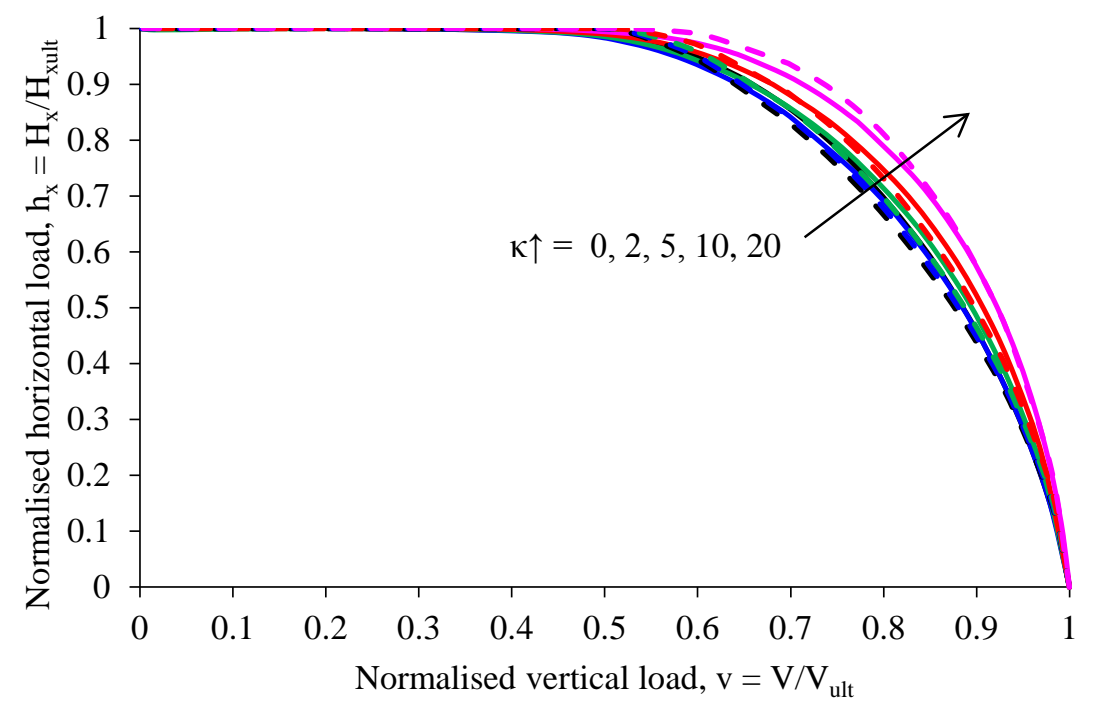

c) $\mathrm{B} / \mathrm{L}=0.75$ 


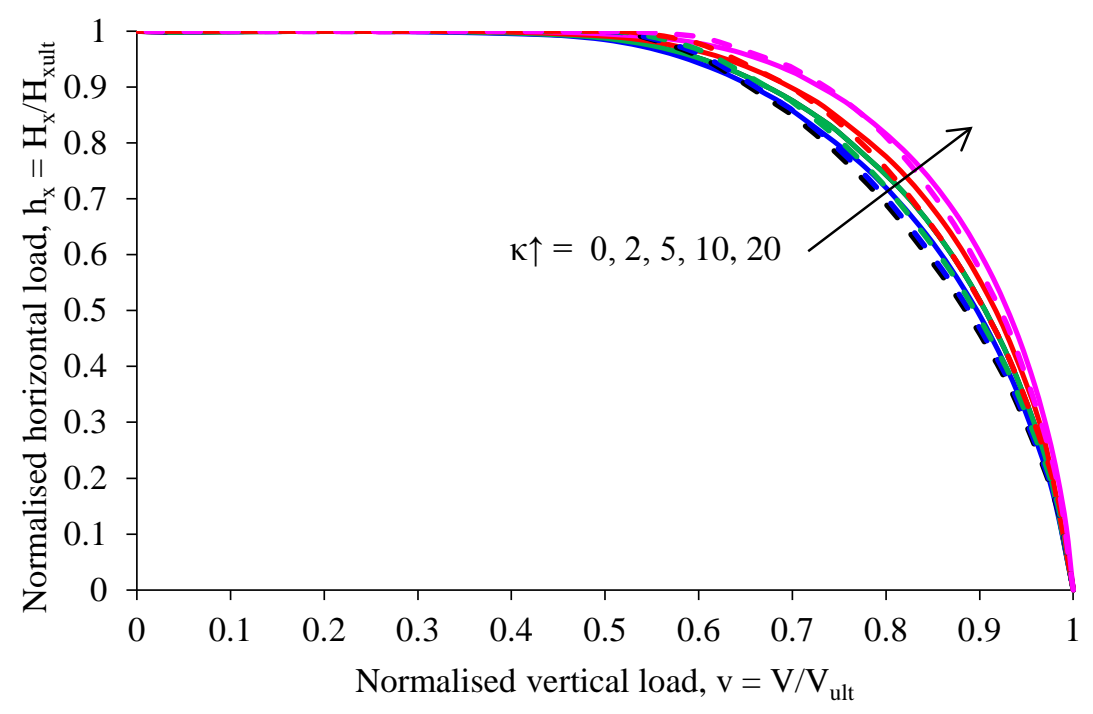

d) $\mathrm{B} / \mathrm{L}=1$

Figure 10 Prediction of the normalised $\mathrm{V}-\mathrm{H}_{\mathrm{x}}$ envelopes for varying $\mathrm{B} / \mathrm{L}$ and $\kappa$

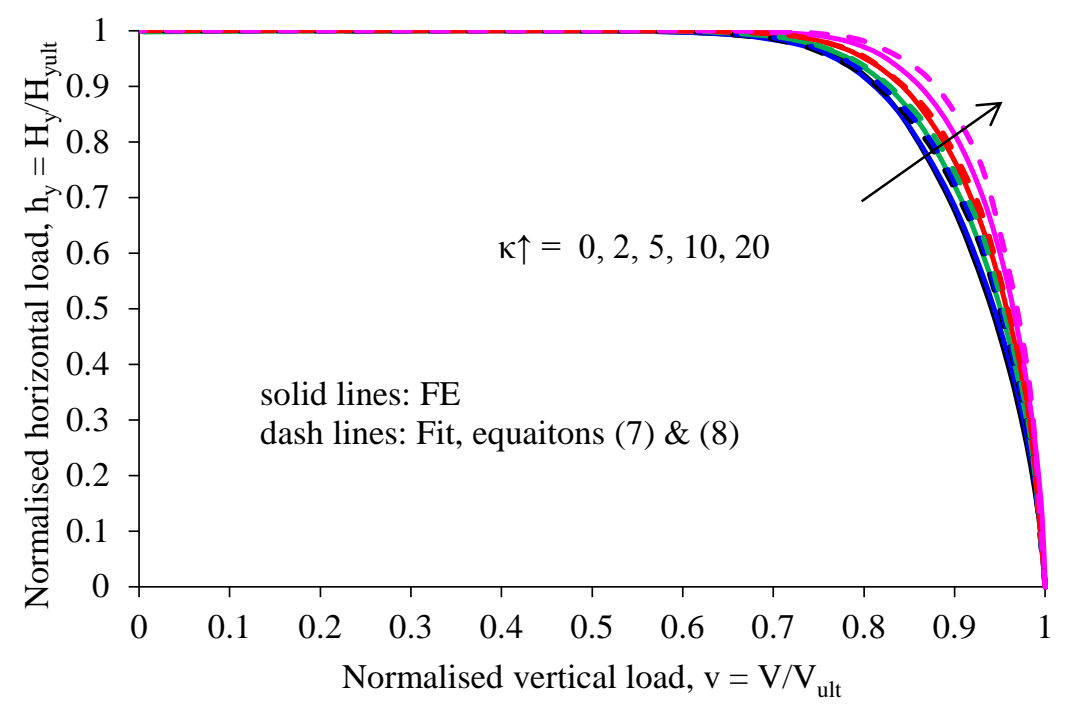

a) $\mathrm{B} / \mathrm{L}=0.2$ 


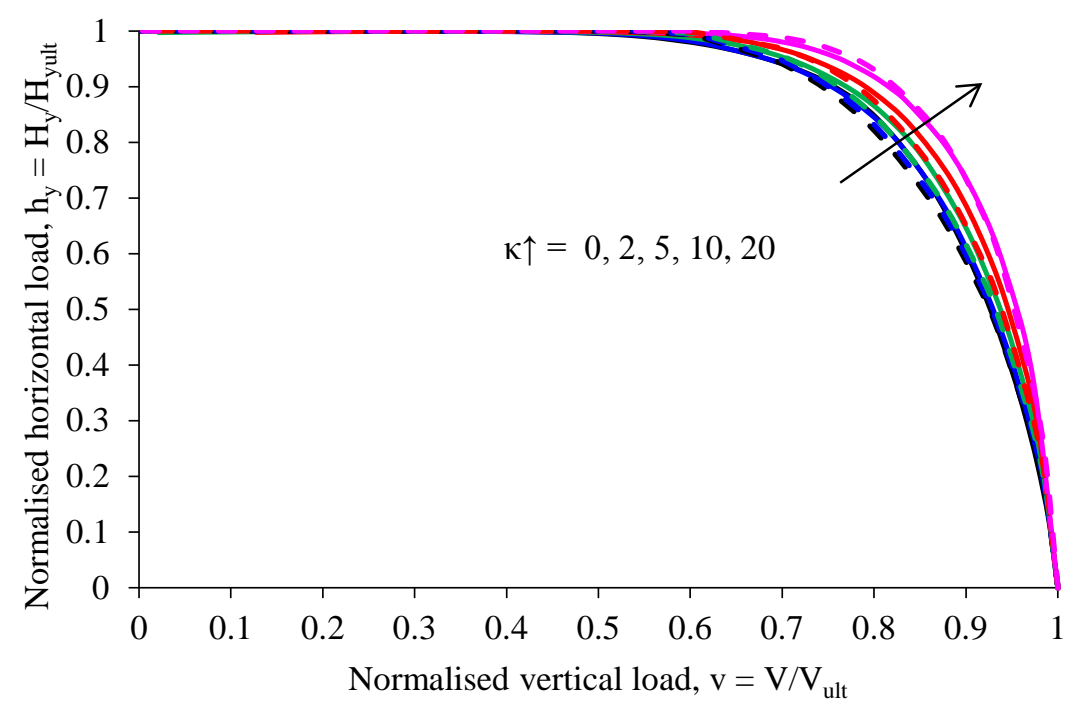

b) $\mathrm{B} / \mathrm{L}=0.5$

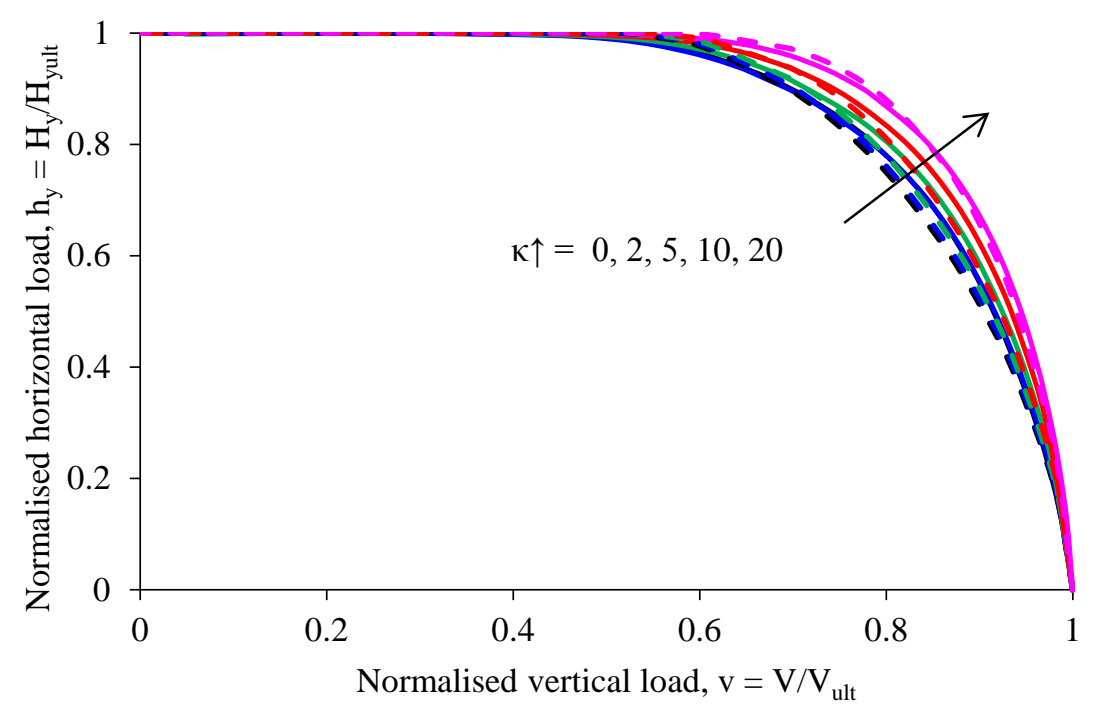

c) $\mathrm{B} / \mathrm{L}=0.75$ 


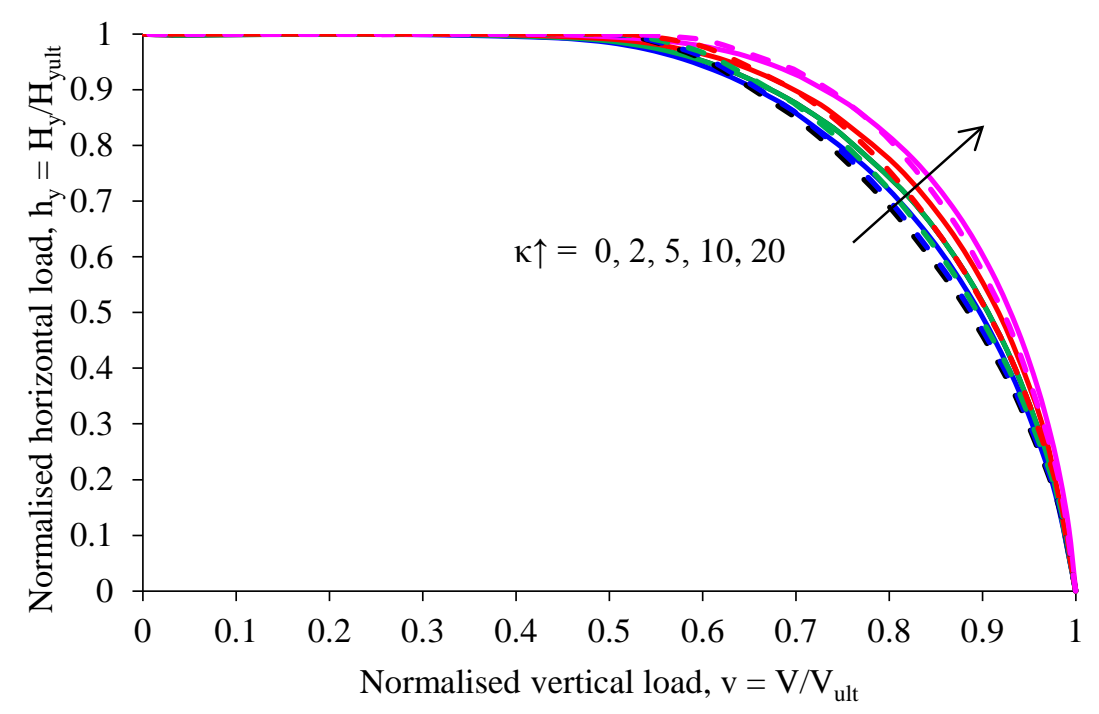

d) $\mathrm{B} / \mathrm{L}=1$

Figure 11 Prediction of the normalised $\mathrm{V}-\mathrm{H}_{\mathrm{y}}$ envelopes for varying $\mathrm{B} / \mathrm{L}$ and $\kappa$

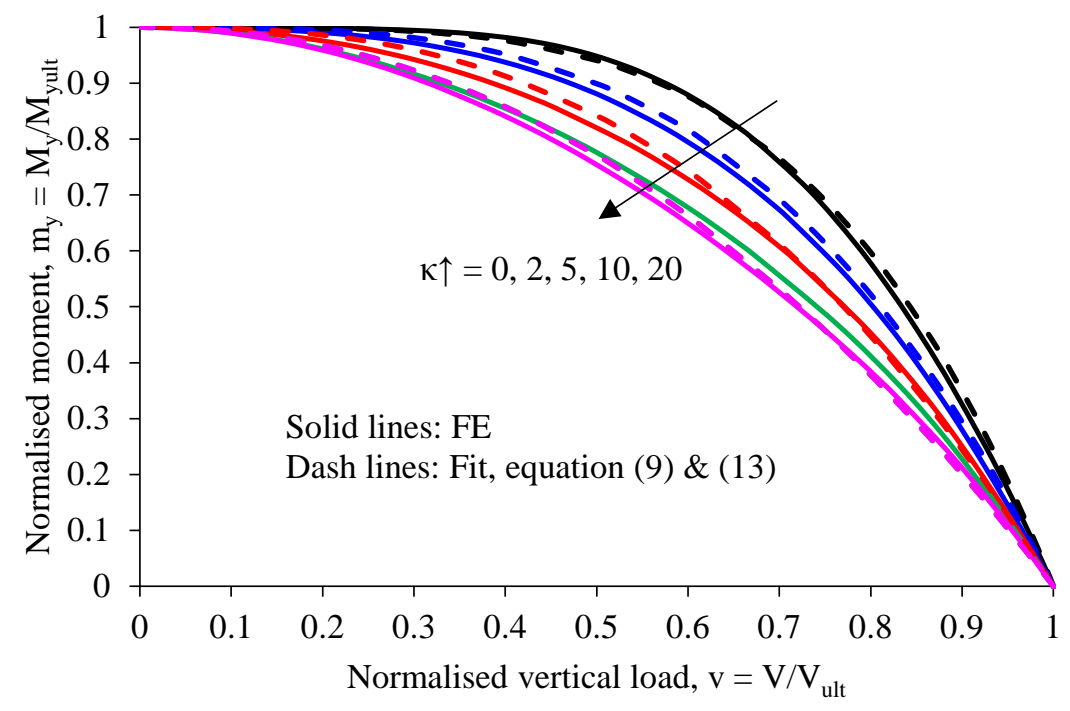

a) $\mathrm{B} / \mathrm{L}=0.2$ 


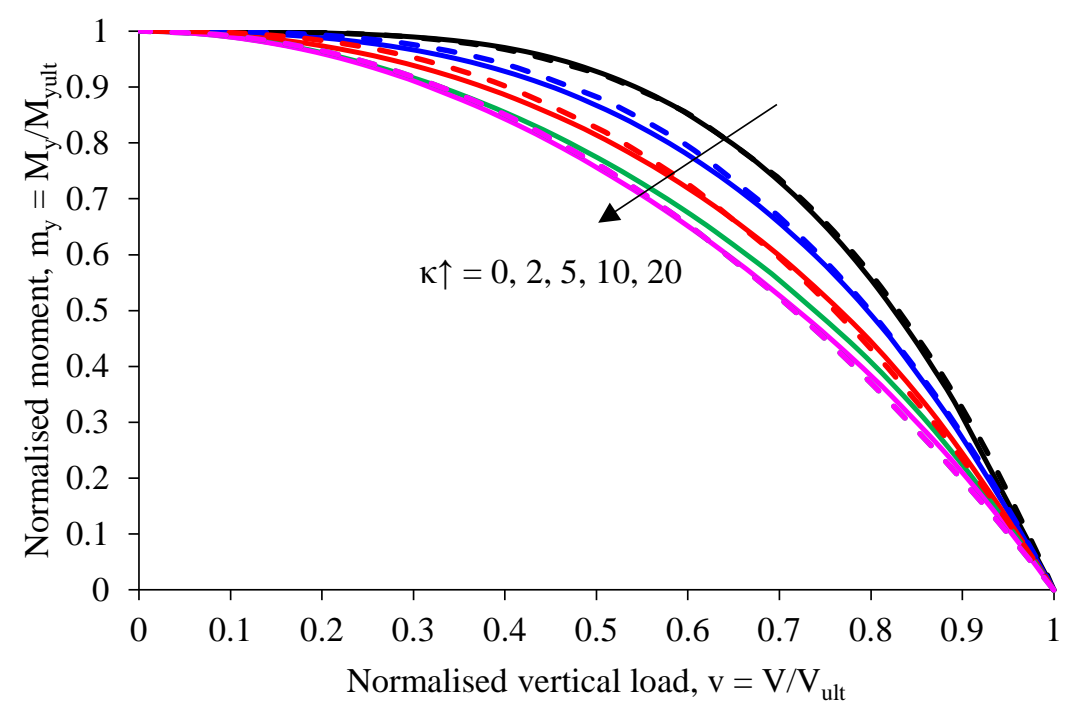

b) $\mathrm{B} / \mathrm{L}=0.5$

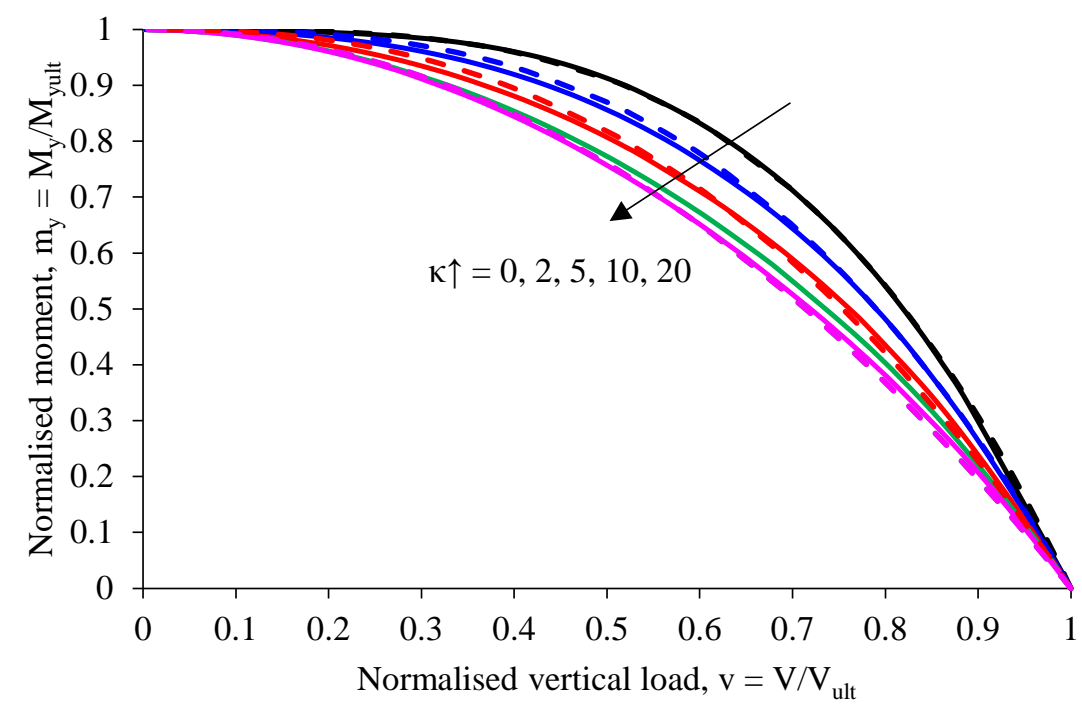

c) $\mathrm{B} / \mathrm{L}=0.75$ 


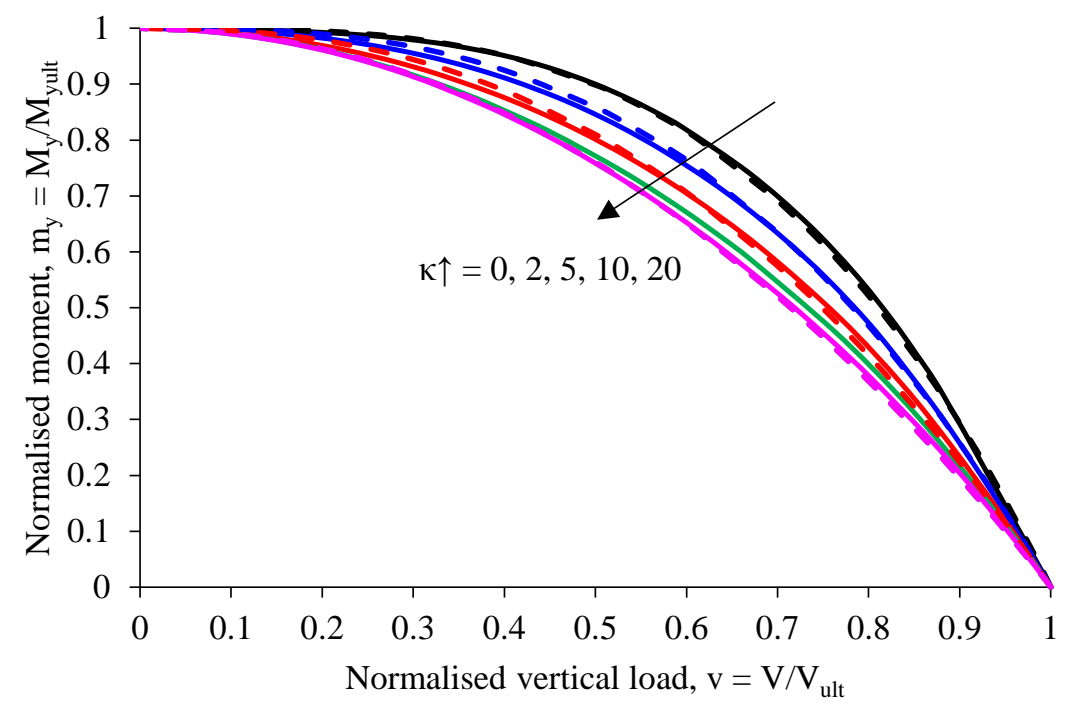

d) $\mathrm{B} / \mathrm{L}=1$

Figure 12 Prediction of the normalised V- $\mathrm{M}_{\mathrm{y}}$ failure envelopes for varying $\mathrm{B} / \mathrm{L}$ and $\kappa$

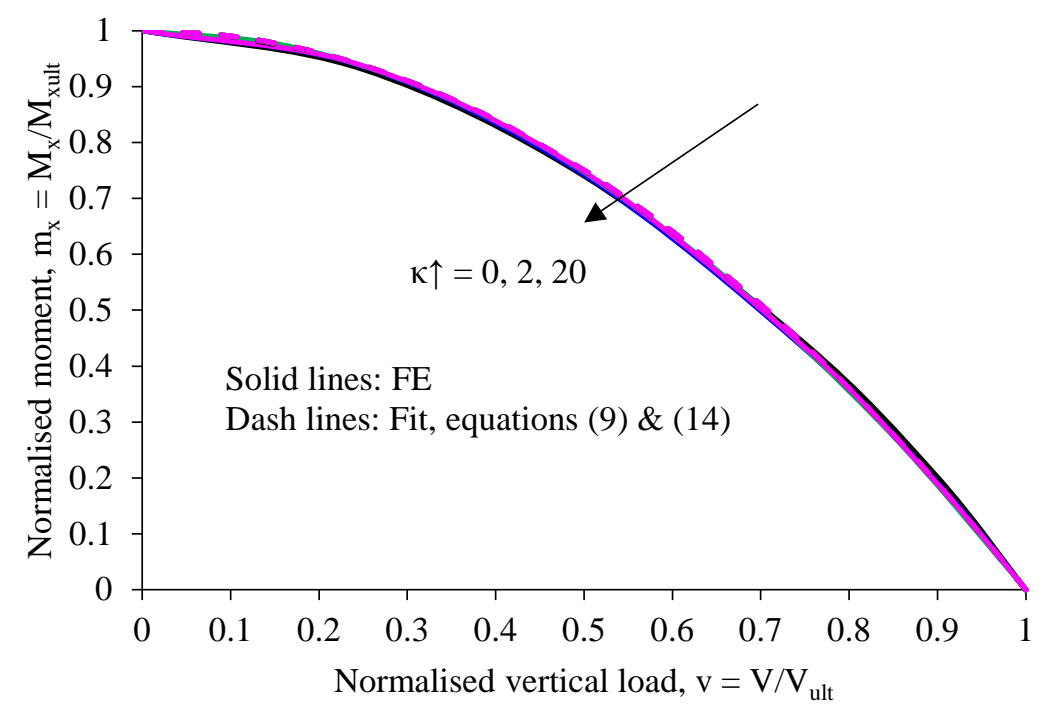

a) $\mathrm{L} / \mathrm{B}=5$ 


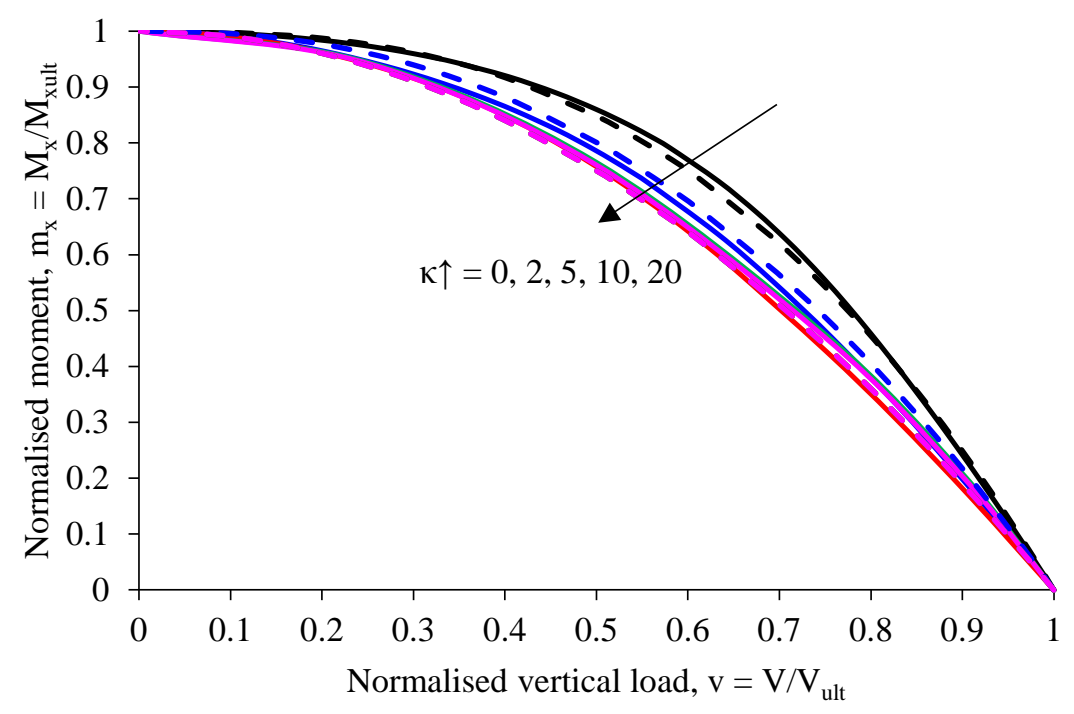

b) $\mathrm{L} / \mathrm{B}=2$

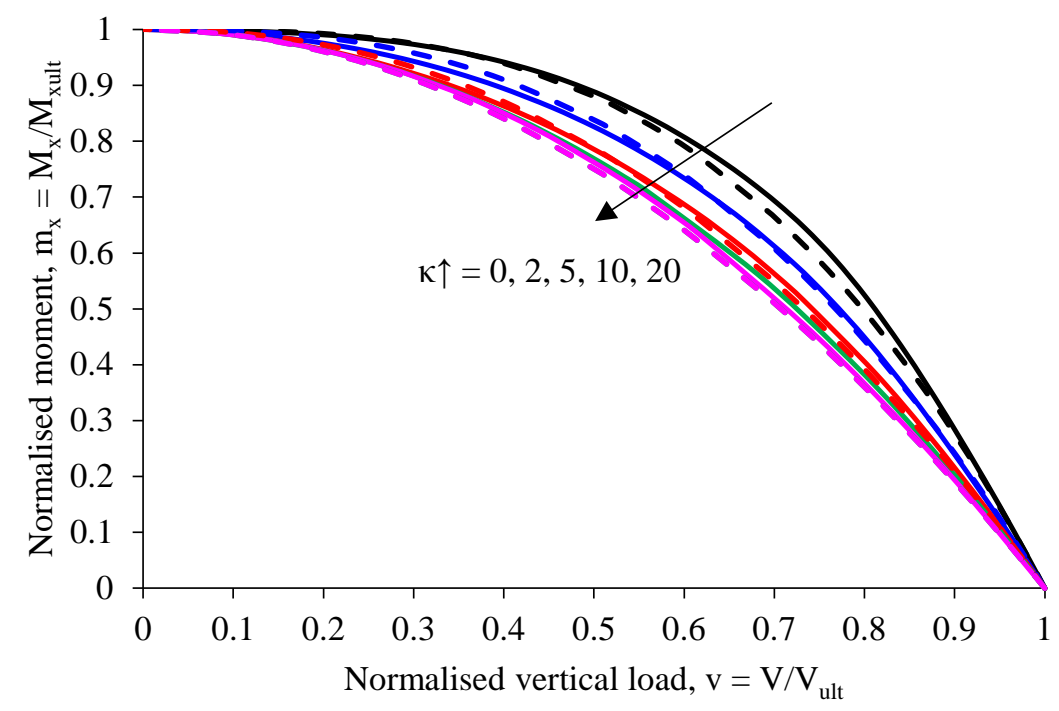

c) $\mathrm{L} / \mathrm{B}=1.33$ 


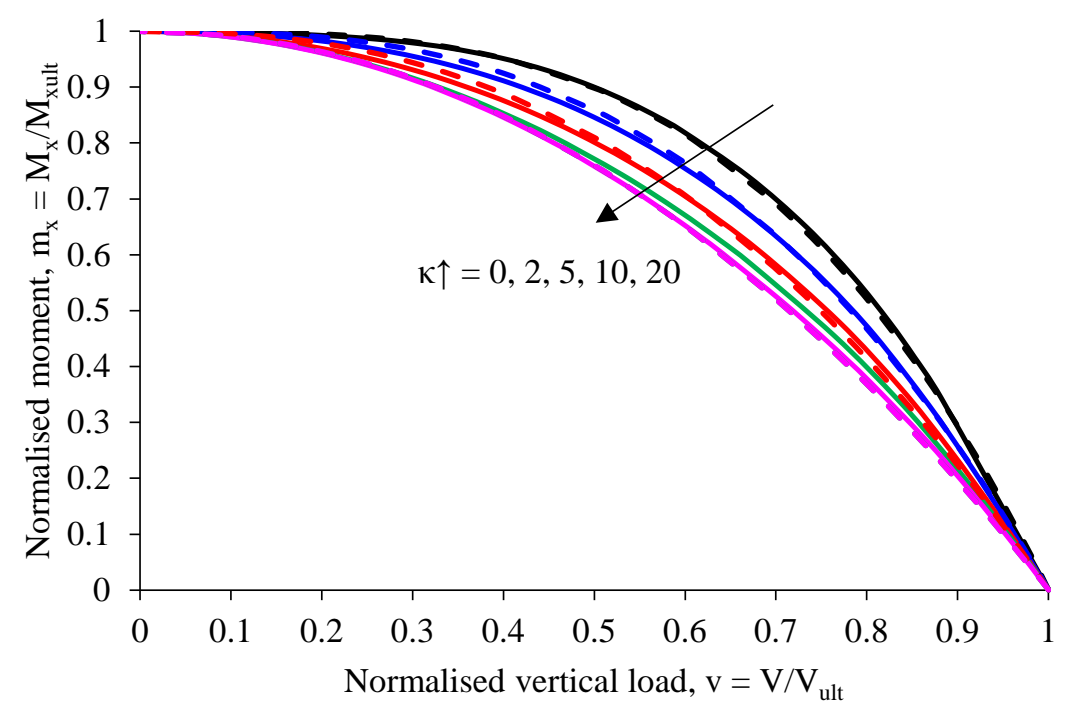

d) $\mathrm{L} / \mathrm{B}=1$

Figure 13 Prediction of the normalised $V-M_{x}$ failure envelopes for varying $B / L$ and $\kappa$

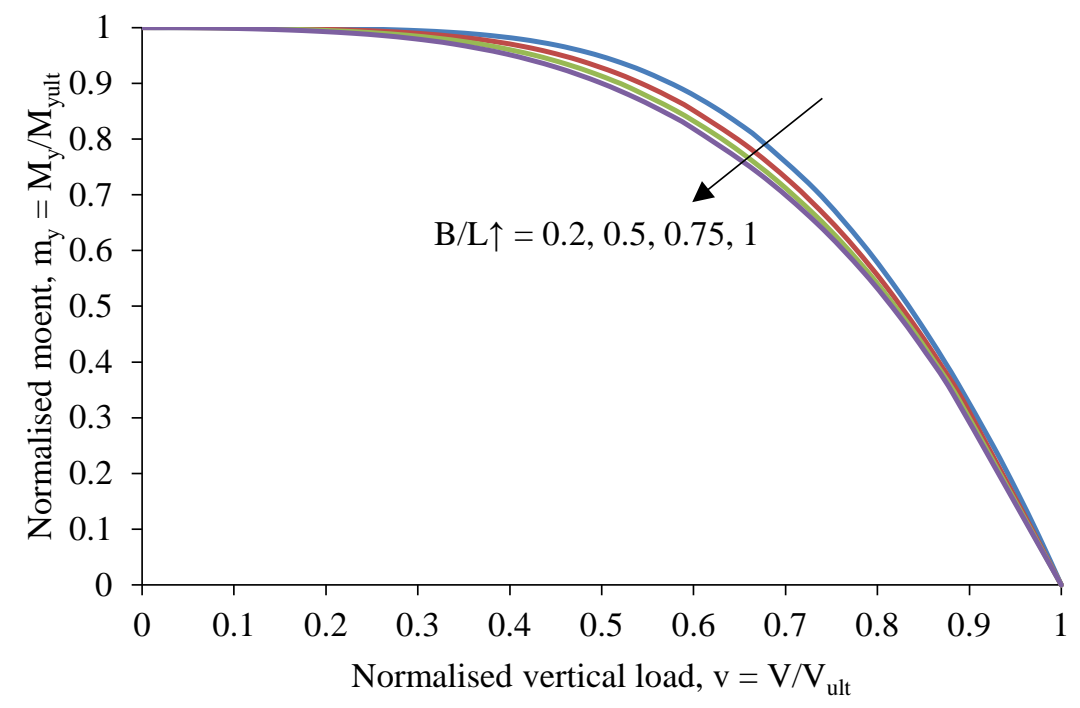

a) $\kappa=0 ; \theta_{\mathrm{m}}=90^{\circ}$ 


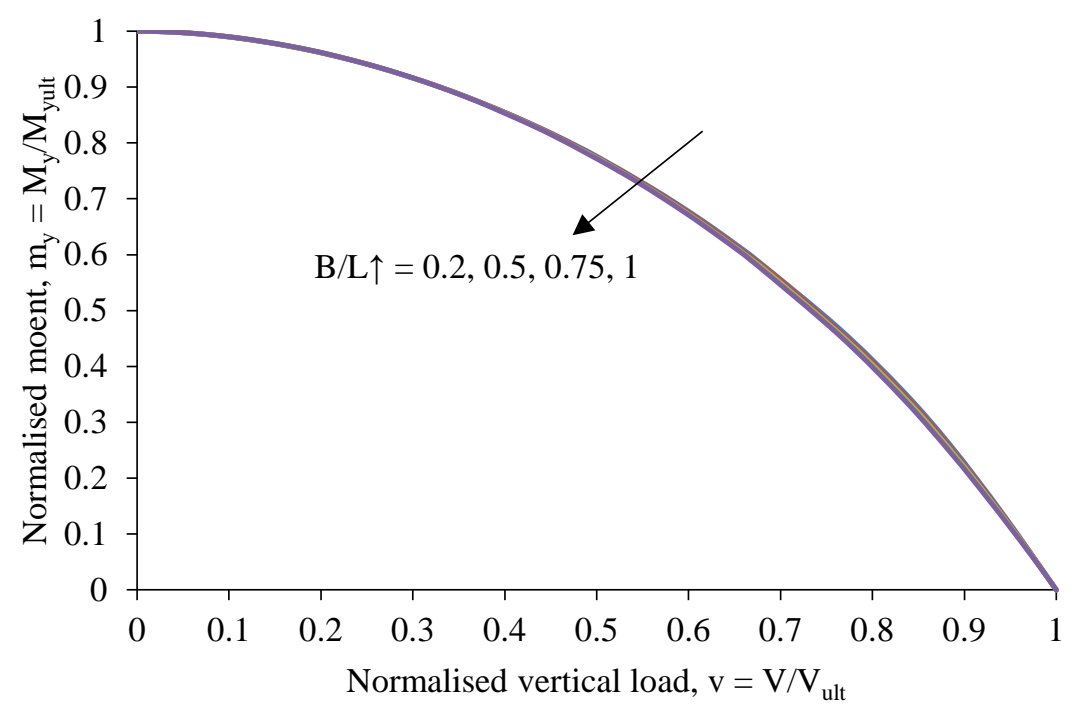

b) $\kappa=10 ; \theta_{\mathrm{m}}=90^{\circ}$

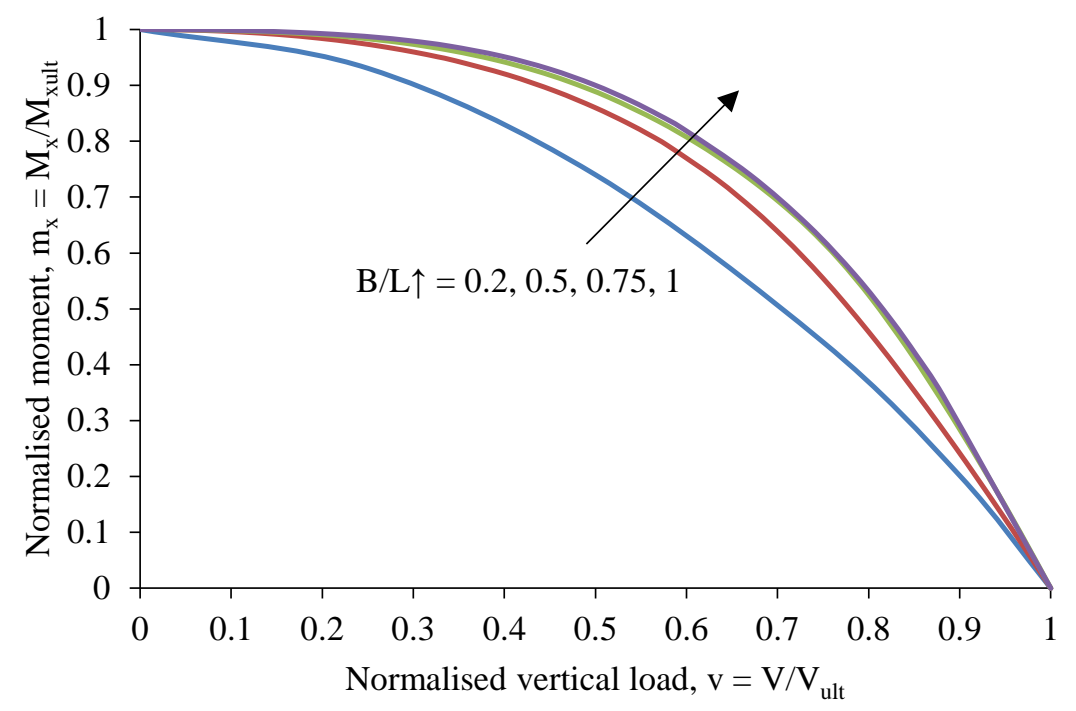

c) $\kappa=0 ; \theta_{\mathrm{m}}=0^{\circ}$ 


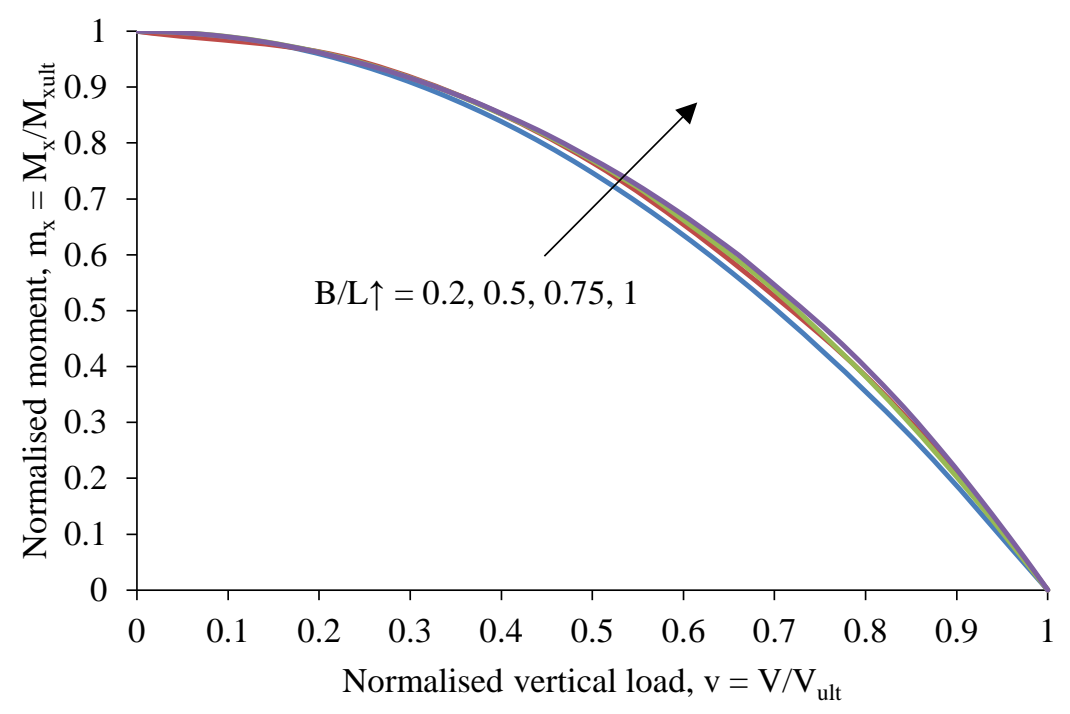

d) $\kappa=10 ; \theta_{\mathrm{m}}=0^{\circ}$

Figure 14 Shape effect on the normalised V-M failure envelopes

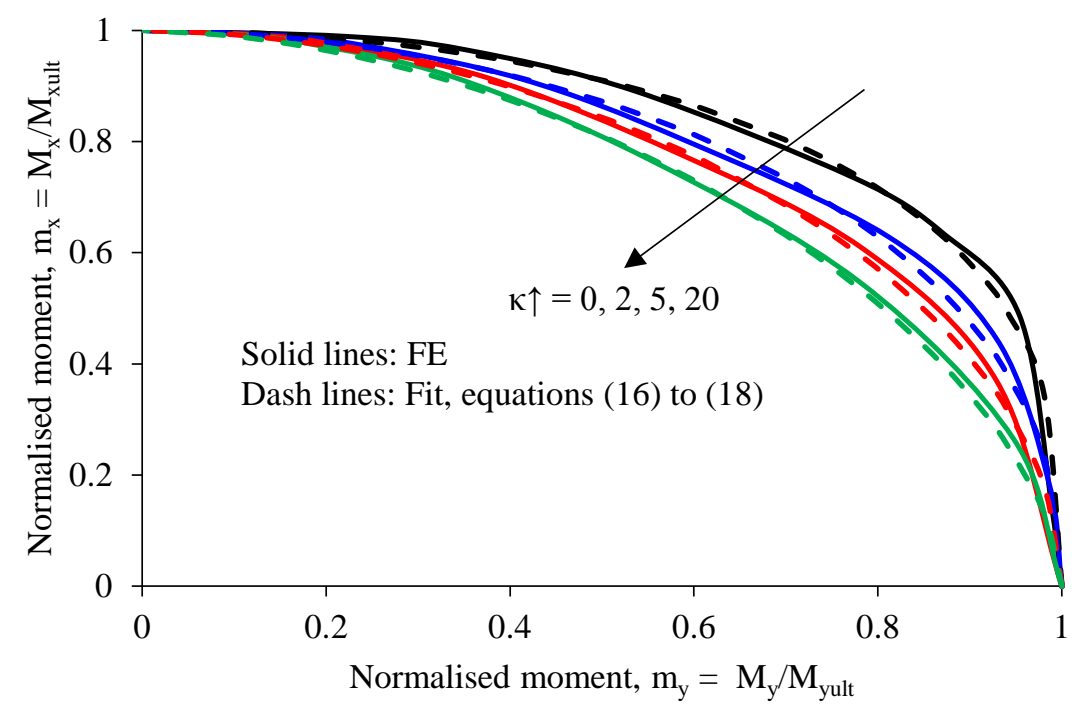

a) $\mathrm{B} / \mathrm{L}=0.2$ 


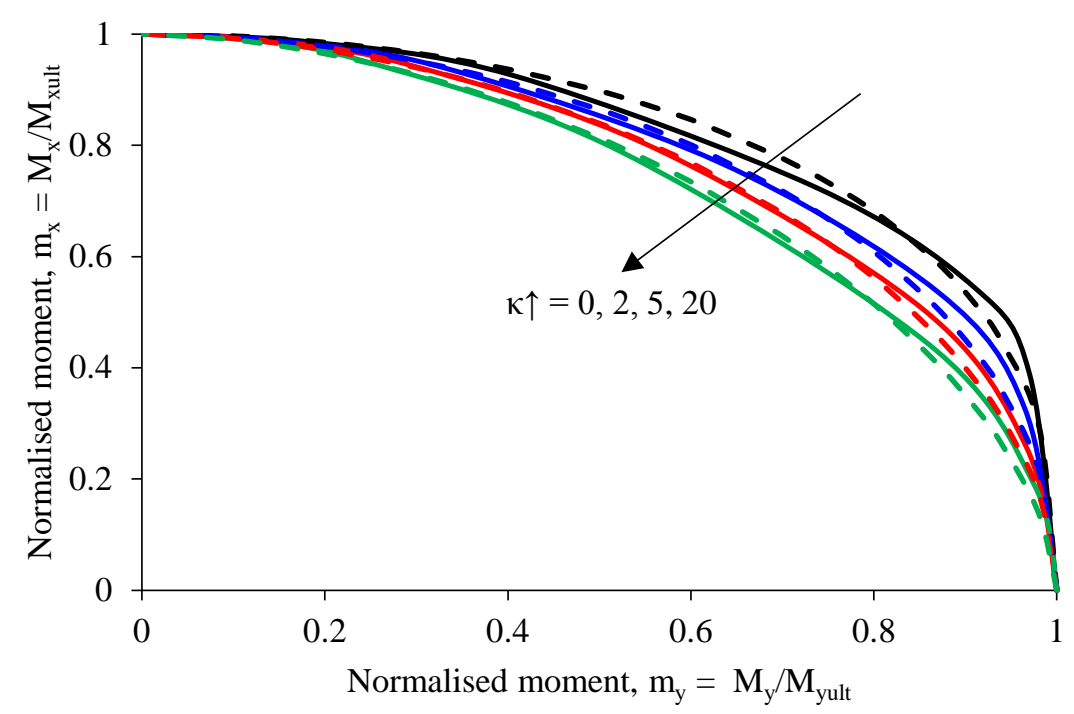

b) $\mathrm{B} / \mathrm{L}=0.5$

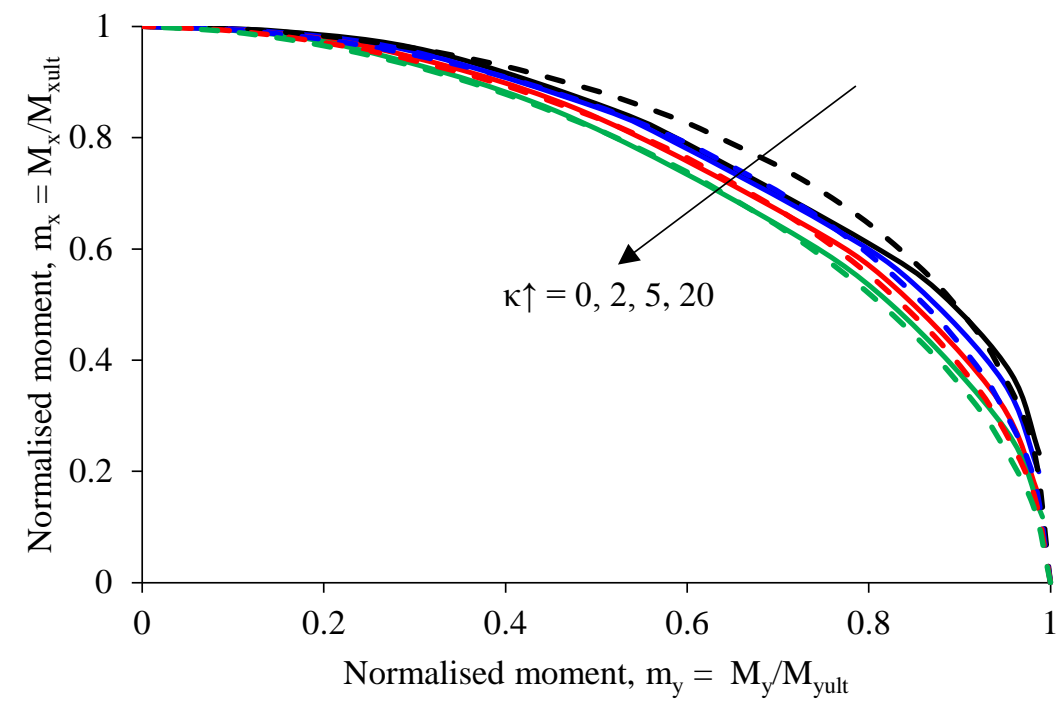

c) $\mathrm{B} / \mathrm{L}=0.75$

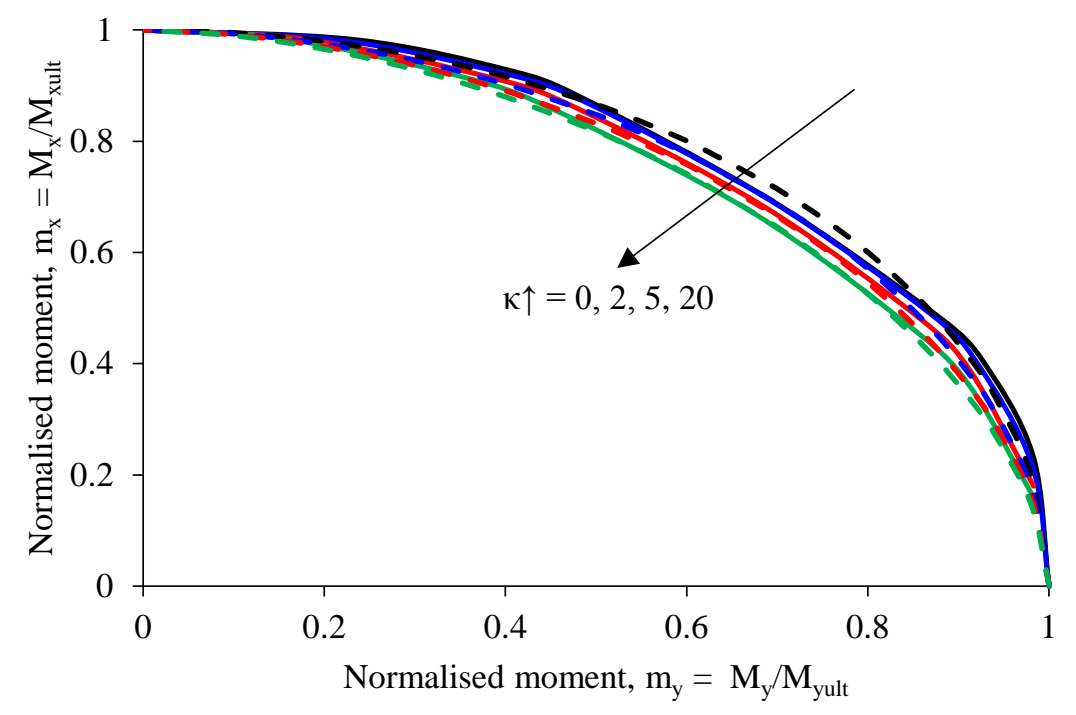


d) $B / L=1$

Figure 15 Normalised $\mathrm{M}_{\mathrm{y}}-\mathrm{M}_{\mathrm{x}}$ failure envelopes for varying $\mathrm{B} / \mathrm{L}$ and $\kappa$

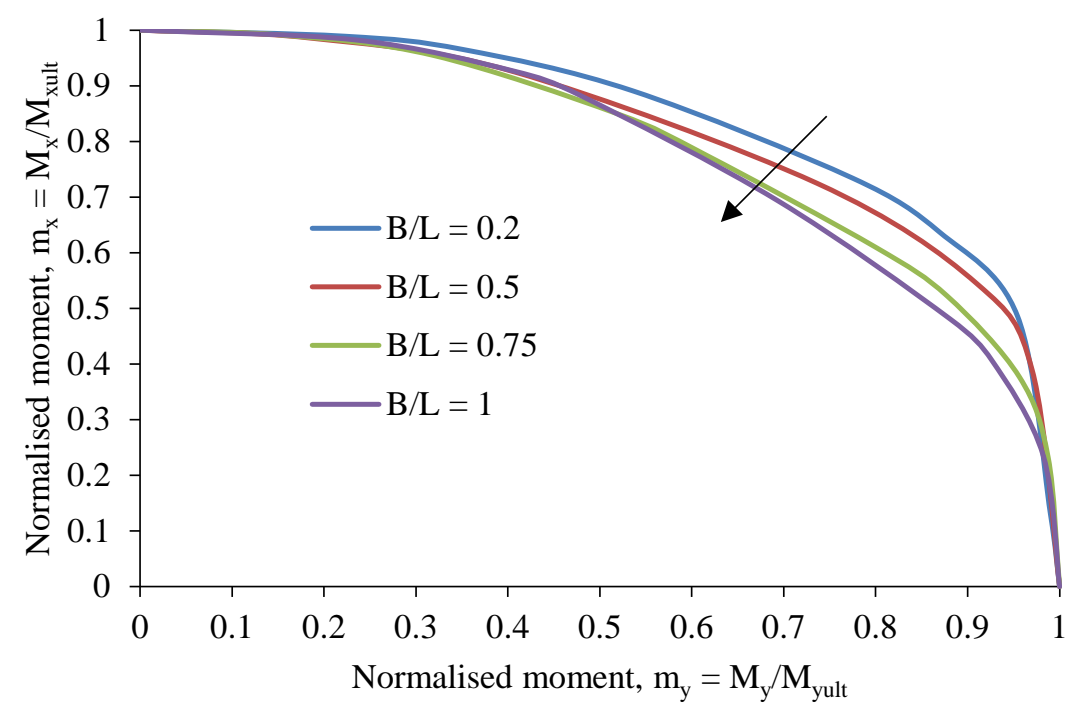

a) $\kappa=0$

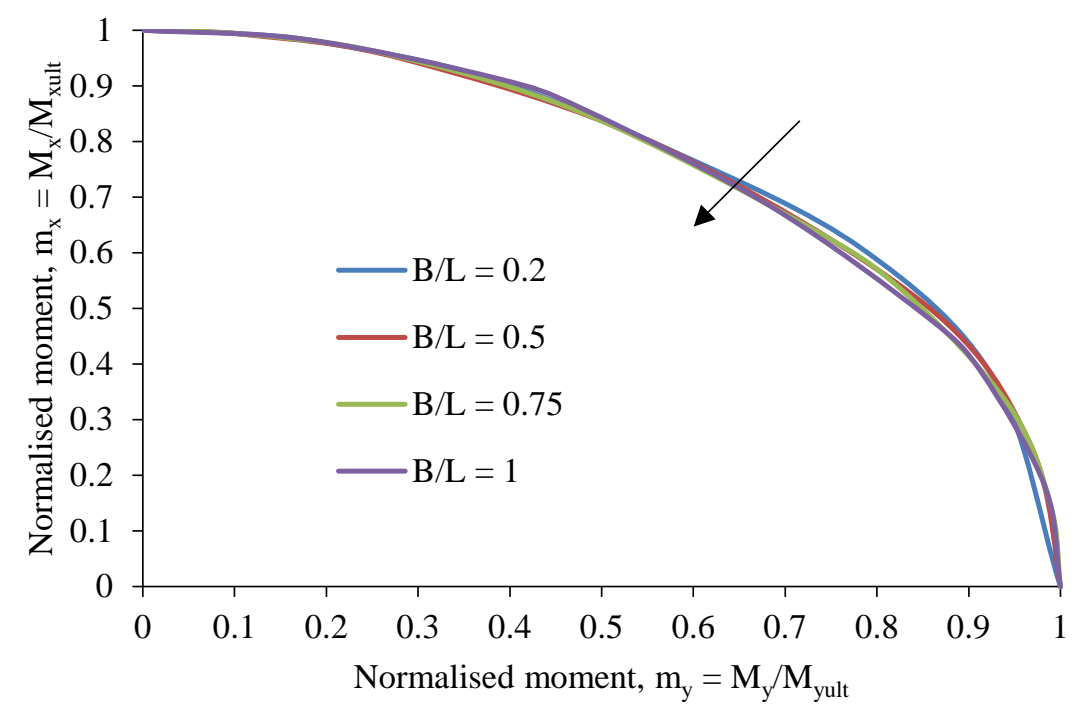

b) $\kappa=5$

Figure 16 Shape effect on the normalised $\mathrm{M}_{\mathrm{y}}-\mathrm{M}_{\mathrm{x}}$ failure envelopes 


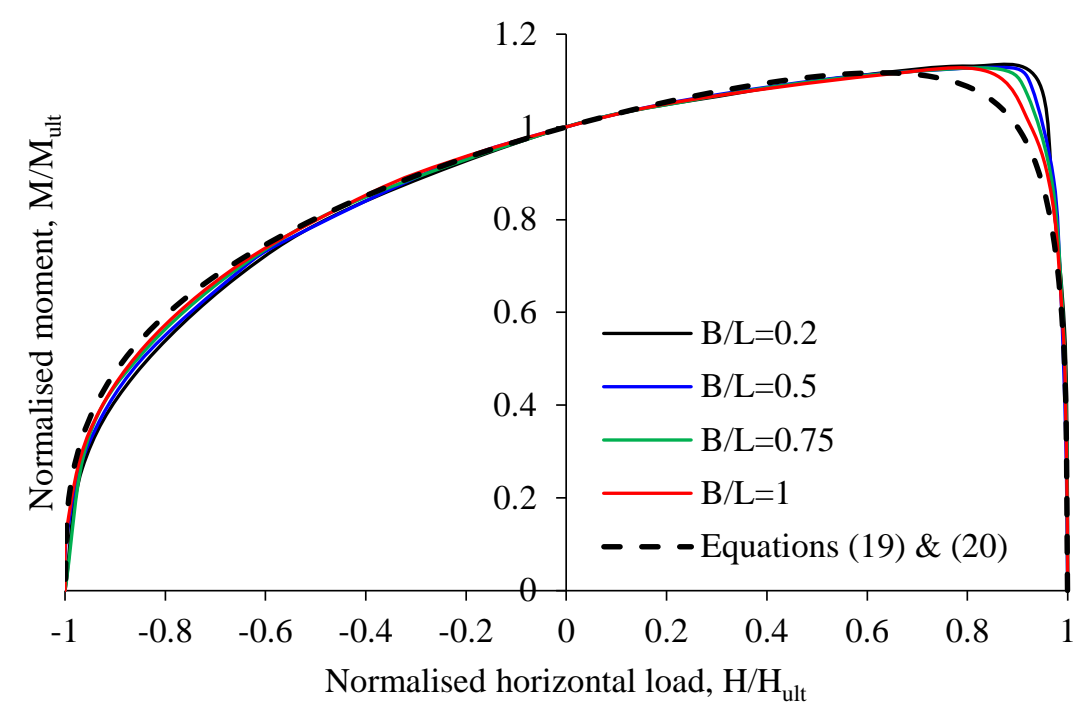

a) $\kappa=0 ; \theta=0^{\circ}$

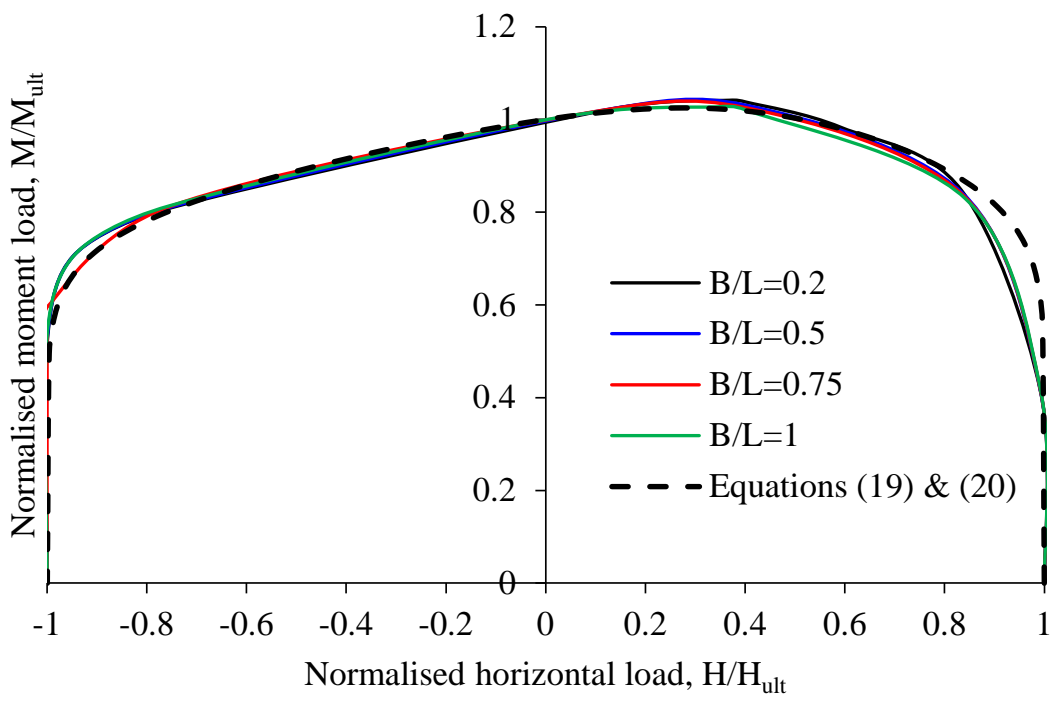

b) $\kappa=20 ; \theta=0^{\circ}$

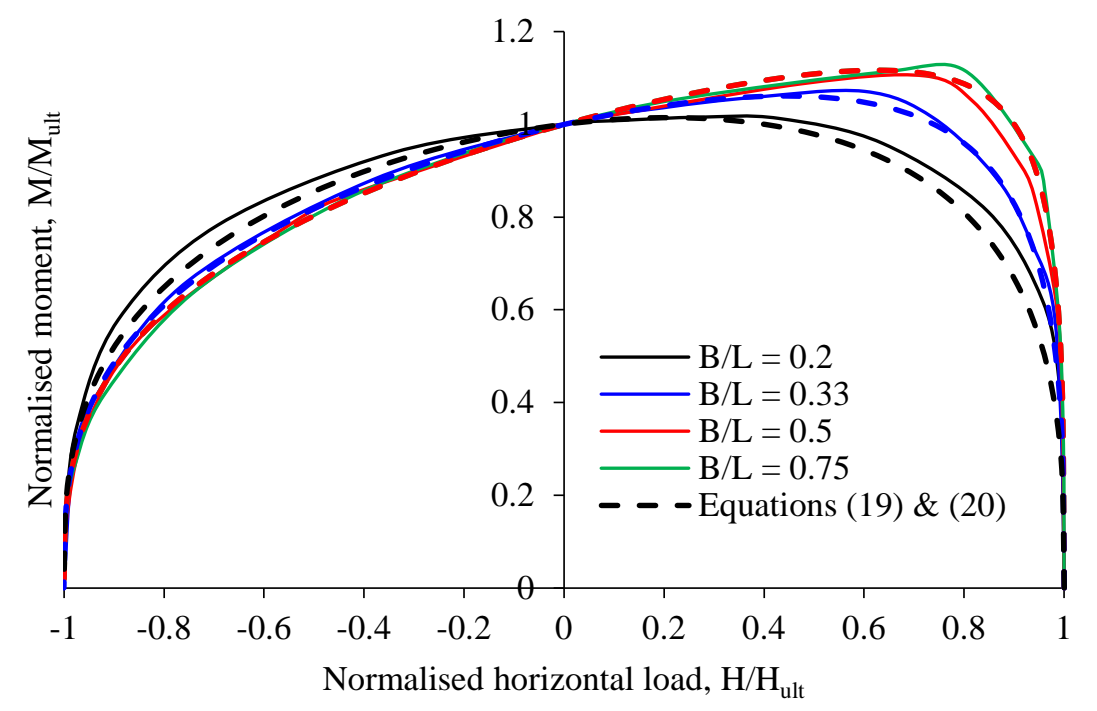


c) $\kappa=0 ; \theta=90^{\circ}$

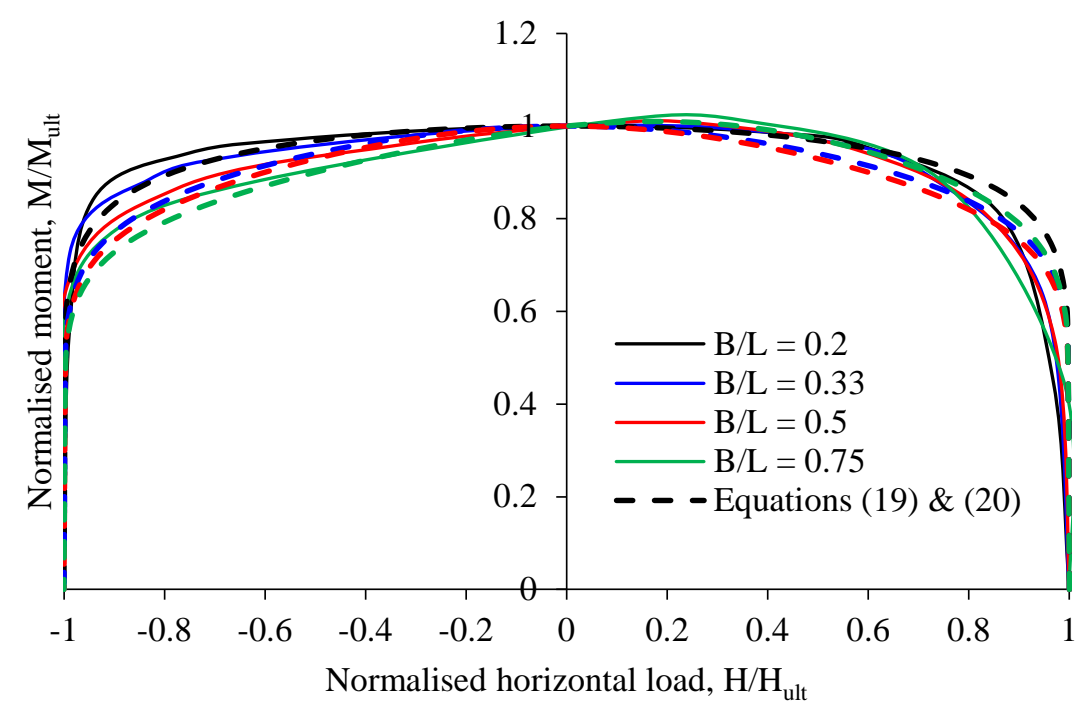

d) $\kappa=20 ; \theta=90^{\circ}$

Figure 17 Effect of aspect ratio and angle of horizontal loading on the normalised $\mathrm{M}-\mathrm{H}$ failure envelopes

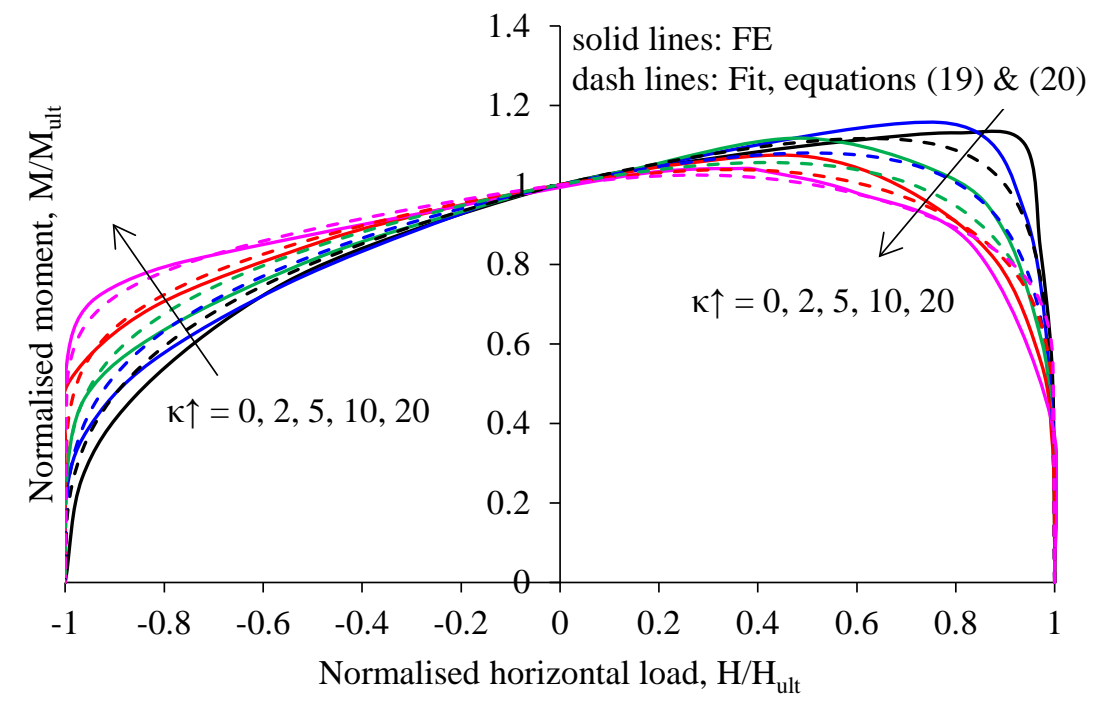

a) $\mathrm{B} / \mathrm{L}=0.2 ; \theta=0^{\circ}$ 


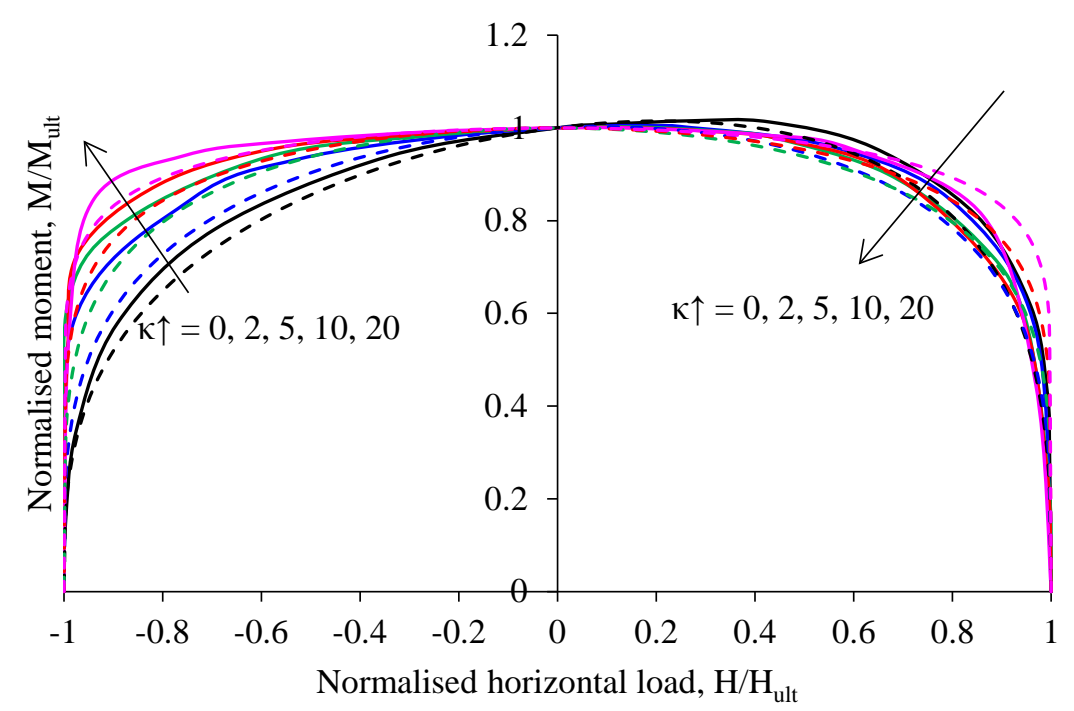

b) $\mathrm{B} / \mathrm{L}=0.2 ; \theta=90^{\circ}$

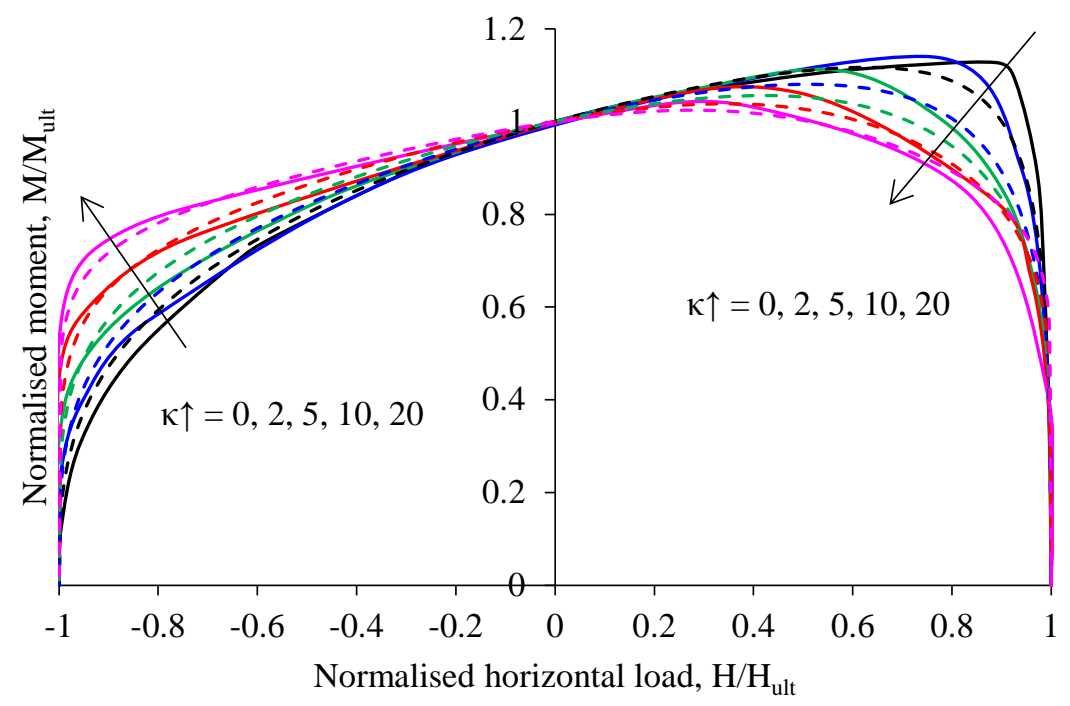

c) $\mathrm{B} / \mathrm{L}=0.5 ; \theta=0^{\circ}$

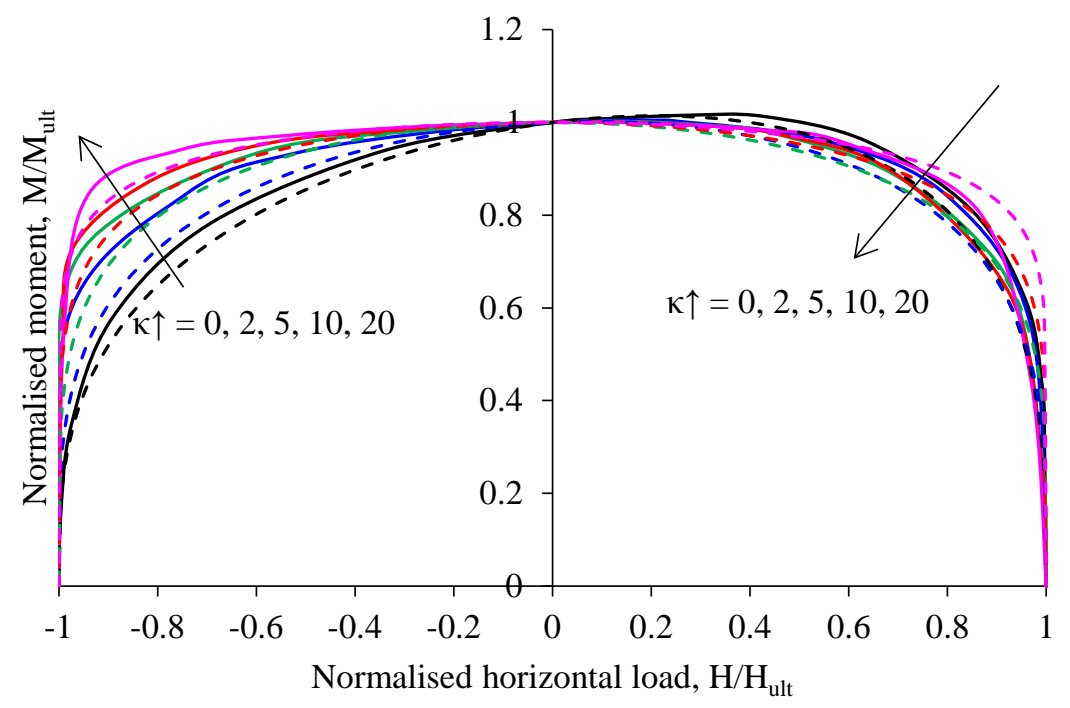


d) $\mathrm{B} / \mathrm{L}=0.5 ; \theta=90^{\circ}$

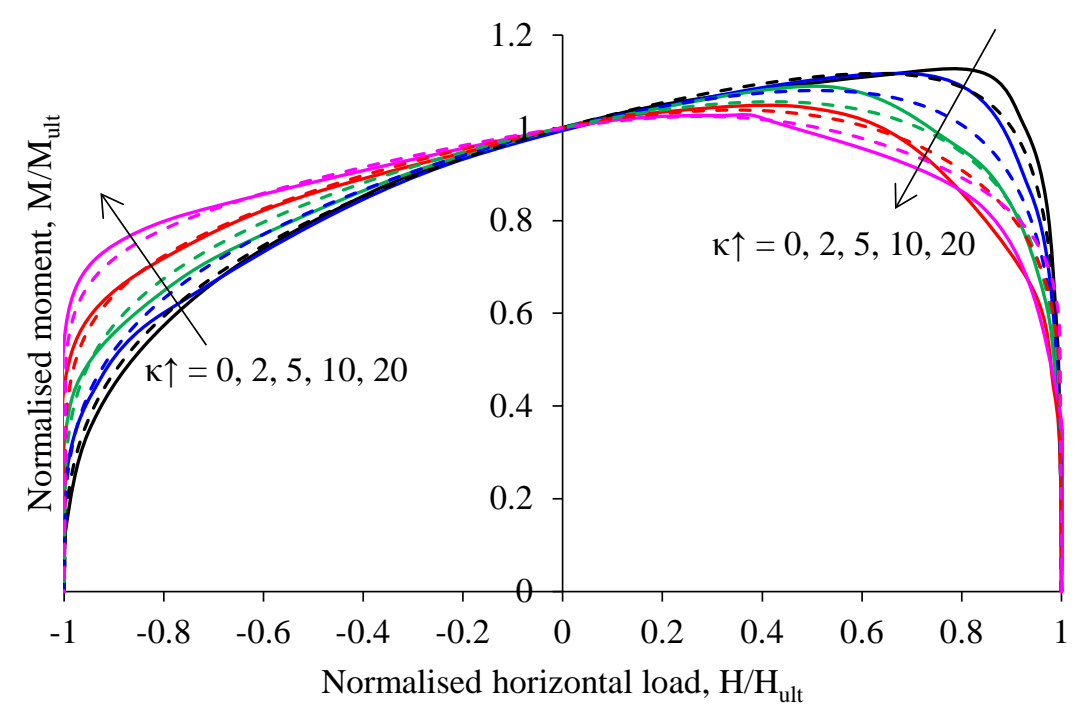

e) $\mathrm{B} / \mathrm{L}=1 ; \theta=0^{\circ}$ or $90^{\circ}$

Figure 18 Effect of degree of soil heterogeneity on normalised $\mathrm{M}-\mathrm{H}$ failure envelopes

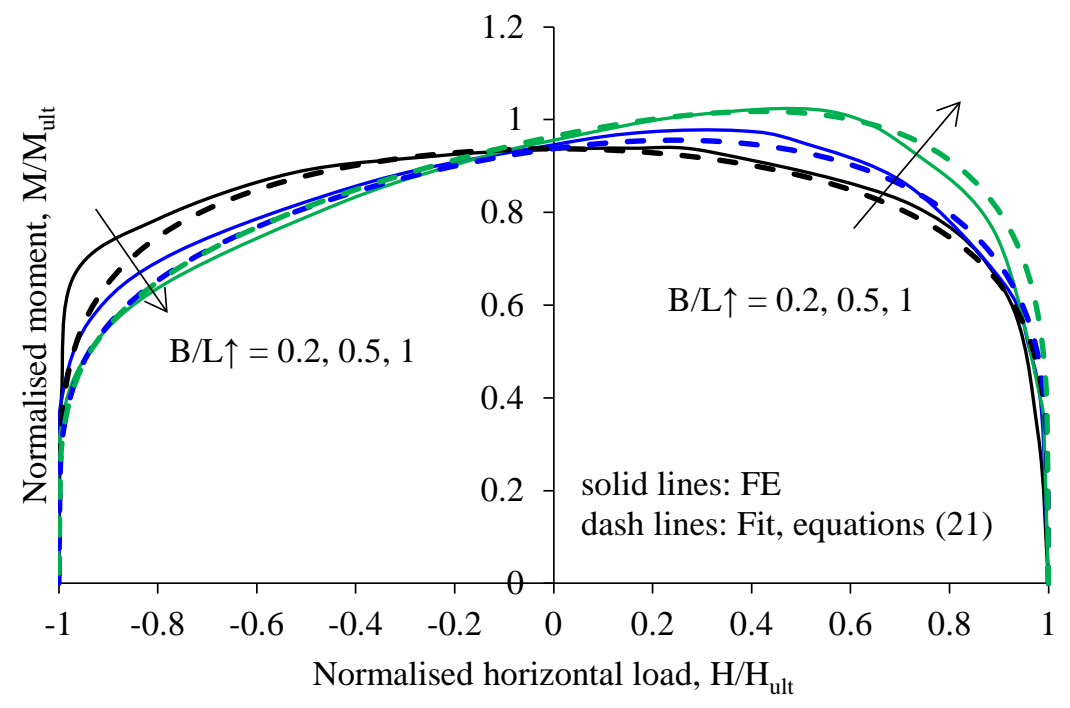

Figure 19 V-M-H failure envelopes in normalised loading space 